\title{
Congressional Representation: Accountability from the Constituent's Perspective
}

\author{
Stephen Ansolabehere Shiro Kuriwaki*
}

August 28, 2020

Forthcoming, American Journal of Political Science

\begin{abstract}
The premise that constituents hold representatives accountable for their legislative decisions undergirds political theories of democracy and legal theories of statutory interpretation. But studies of this at the individual level are rare, examine only a handful of issues, and arrive at mixed results. We provide an extensive assessment of issue accountability at the individual level. We trace the congressional rollcall votes on 44 bills across seven Congresses (2006-2018), and link them to constituent's perceptions of their representative's votes and their evaluation of their representative. Correlational, instrumental variables, and experimental approaches all show that constituents hold representatives accountable. A one-standard deviation increase in a constituent's perceived issue agreement with their representative can improve net approval by 35 percentage points. Congressional districts, however, are heterogeneous. Consequently, the effect of issue agreement on vote is much smaller at the district-level, resolving an apparent discrepancy between micro and macro studies.
\end{abstract}

Keywords: Electoral Accountability, Representation, Congress, Rollcall Voting.

Replication Materials: The data, code, and any additional materials required to replicate all analyses in this article are available on the American Journal of Political Science Dataverse within the Harvard Dataverse Network, at: https://doi.org/10.7910/ DVN/QOVWMM (pending review by AJPS).

*Stephen Ansolabehere (sda@gov.harvard.edu; http://scholar.harvard.edu/sansolabehere) is Frank G. Thomson Professor of Government and Shiro Kuriwaki (kuriwaki@g.harvard.edu; https://www. shirokuriwaki. com) is Ph.D. Candidate, both in the Department of Government at Harvard University, 1737 Cambridge St, Cambridge, MA 02138. We thank Mathias Tromborg and participants at EPSA 2018, Chris Tausanovitch and participants at SPSA 2019, as well as David Broockman, Christopher Cochran, Sebastian Thieme, Soichiro Yamauchi, and workshop participants at the University of California Santa Barbra, University of Texas Austin, Arizona State University, Princeton University, and Harvard University for their comments and suggestions. We acknowledge partial support from NSF Award Number SES-1756447 and the Harvard FAS Dean's Competitive Fund. Authors listed alphabetically. 
Representative democracy rests on a simple idea. Constituents elect politicians to be their agents in passing laws and setting public policy. If an individual constituent disagrees with the actions or decisions of a representative, the constituent may choose someone else at the next election. A majority of the electorate can elect another legislator or party to represent them. Modern political science has taken this notion of accountability as the cornerstone for theorizing about representation and for studying law-making in representative democracies, especially within the American Congress (Mayhew 1974). Constitutional theory and even Supreme Court doctrine treats electoral accountability as the wellspring of legislative and executive authority in the U.S. (Eskridge 1987).

As important as the classical theory of accountability is, it is ultimately just a theory. The empirical foundations for this idea are, as Stephanopoulos (2018) recently surmised, underdeveloped. One significant line of research has established a connection at the district-level between the legislator's congruence with their district and election results (Canes-Wrone et al. 2002). But as Carson et al. (2010) suggest, without constituent-level data, these aggregate estimates might also reflect party loyalty, ideology, presidential approval or other factors. A second line of research has explored the individual foundations for electoral accountability. In their path-setting article, Miller and Stokes (1963) concluded that most constituents lack the knowledge to hold their representatives accountable and, as a result, that there is low congruence between constituents and legislators.

The conclusion that Miller and Stokes reached has spawned a very different view of congressional politics in the U.S. than that embraced in the classical theory of representation. If voters cannot exert electoral accountability, representation breaks down. That gives elites, such as interest groups, policy ideologues, or wealthy donors, an opening to capture the political process (Bartels 2008; Bawn et al. 2012). Bawn et al. (2012) challenge the notion that "to win elections politicians must do what voters want". They argue "voters do not pay so much attention to politics," and those "limitations of most voters to hold their legislators accountable" creates the conditions for extreme partisanship in Congress (p.589-590). Has 
the constituents' side of the accountability mechanism actually broken down?

Scholarship in the past two decades has repeatedly debated the questions raised by Miller and Stokes. Clinton (2006) and Bafumi and Herron (2010) used key votes in Congress as better measures of ideological congruence, and Ansolabehere and Jones (2010) and Guisinger (2009) provided evidence that individual constituents reward representatives with whom they perceive to be in agreement on specific rollcall votes. Since those initial studies, the debate over whether partisan constituents can hold their representatives accountable on issues has intensified. Several studies have argued that partisanship distorts people's perceptions and swamps issue voting (Lenz 2012; Broockman and Butler 2017), but others reach opposite conclusions (Bullock 2011; Fowler 2020).

Here we offer an extensive empirical assessment of congressional accountability, tracing representative's roll call votes to constituent's perceptions about those specific votes, and finally from those pictures in people's heads to the electoral evaluations that they make of their representatives. We study the entire 12-year span of the Cooperative Congressional Election Study (CCES), which covers over 67 roll call votes and asks constituent's perception on 44 of them. Dramatic swings in political control of the U.S. government from 2006 to 2018 mean that our study captures nearly every political constellation: unified Republican control, unified Democratic control, divided control with a Republican President and a Democratic Congress, and divided control with a Democratic President and a Republican Congress. The key votes we track reflect the wide-ranging policy agenda during this time, including war, health care, trade, banking, wages and labor discrimination, the budget and taxation, welfare programs, immigration, crime, guns, education, abortion, agriculture and gay rights.

This study contributes to four foundational questions on electoral accountability. We significantly extend past findings on these questions with new data and designs, and we reconcile seemingly contradictory claims in the literature.

First, what is the relationship between legislators' congruence with their constituents and constituents' evaluations of their legislators? Consistent with past work we find that 
an individual constituent's agreement between representatives lead to positive evaluations of that representative. In contrast to the work that focuses on ideological agreement, we also measure agreement in terms of the specific votes Members of Congress cast. We find that agreement on these key votes affects evaluations even after controlling for agreement in terms of party affiliation and latent ideology, suggesting that each key vote matters. We call this relationship the reduced form because it is simply the relationship between what legislators do and what voters do, and does not establish the mechanism operating in voters' minds.

Second, are constituent's perception of their representative's actions in Congress accurate? This is the critical first step in the accountability process. Do people have, to use Walter Lippmann's expression, a picture in their heads about how their representatives voted, and is that picture close to reality? The answer is largely yes. Most people have a belief about how their representatives voted, and among those who provided an answer, a majority have the correct belief about their representative's votes. To the extent that there is slippage, it takes two forms: uncertainty and misperception. About two in five people do not readily express a belief about how their representatives voted on the average bill. Also, co-partisans tend to perceive more issue agreement than actual agreement, but these biases appear to be second-order effects compared with the main effect of correct issue perception.

Third, do constituents in fact support representatives because they think they agree on key legislation that Congress has voted on, independently from party? Or, is the correlation between issue agreement and evaluation actually partisan projection (Lenz 2012)? We start with difference-in-means estimates suggesting that perceived issue agreement has independent effects on approval and vote choice. We then replicate the instrumental variable identification strategy of Ansolabehere and Jones (2010), albeit over a much wider span of time and issues. Finally, we conduct two survey experiments and conduct sensitivity analyses to address the concerns that the instrumental variable conditions may not hold. These correlational, instrumental variable, and experimental approaches all show that perceived 
issue agreement on key legislation does translate into electoral support, and the effects are substantial and operate independent of party.

Fourth, why are the individual-level effects of issue accountability so much larger than the district-level effects, as noted by Tausanovitch and Warshaw (2018)? Studies using survey data at the individual-level typically report a 10 to 20 percentage point effect of congruence on an individual's vote choice (Jessee 2009; Ansolabehere and Jones 2010; Shor and Rogowski 2018). Yet Canes-Wrone et al. (2002) find that House members gain only 1 to 3 percentage points of their voteshare from moderating towards the party's median rather than from voting at the extreme of their party (see also Fiorina 1974; Erikson et al. 2002; Bonica and Cox 2018). We show that the tension results from the aggregation of individual voters to the district level. Congressional districts are sufficiently heterogeneous that a Member of Congress voting on the side of the majority of her constituents would still disappoint a sizable minority. As a result, even when many constituents care about and are knowledgeable about salient issues and when a representative votes with the majority in a district, the aggregate congruence can come out quite low. This does not mean that issues are unimportant, because voting against the district majority would be even more costly.

In what follows, we uncover a picture of the electorate that, while not hyper-informed and hyper-rational, is one in which constituents are sufficiently attentive that the majority can and does hold their representatives accountable for the decisions that they make on important pieces of legislation.

\section{Models AND MethodS}

We start by outlining our model of constituent accountability, setting up our identification strategy, and describing how we combine CCES data, experiments, and roll call votes on the House floor to identify these mechanisms. 


\section{Figure 1 - Accountability from the Constituent's Perspective}

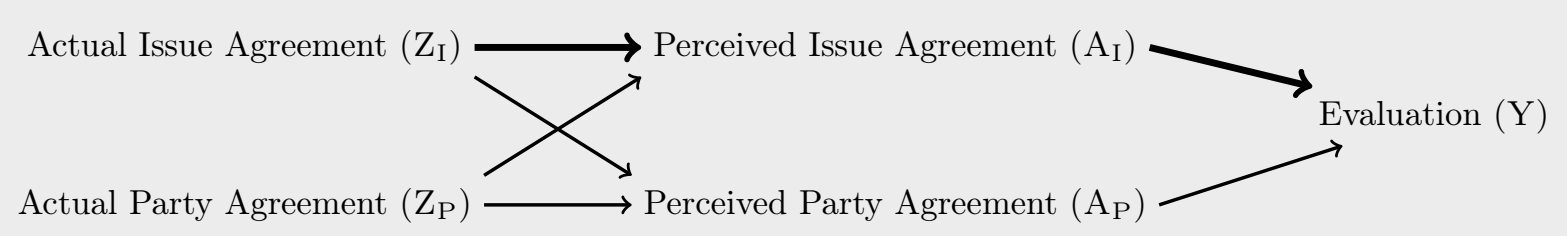

Note: Arrows show possible causal effects, and bold arrows show issue accountability. This is a Directed Acyclic Graph (DAG) for our estimation strategy. The random variables we use to denote each concept are shown in parentheses. Control variables and unobserved confounders are not shown for clarity but are addressed in the main text.

\section{A Model of Reality, Perception, and Evaluation}

Figure 1 depicts the causal process of issue accountability. We trace the bolded arrows from left to right: In the initial stage, representatives belong to a party, they cast a vote on an bill, and constituent's have a preference for that bill as well. A representative and her constituent are in actual issue agreement when they have the same preferences.

The subtlety in testing theories of accountability is that constituents can only act on what they know (Gilens 2001). Therefore we distinguish between two sorts of agreement in Figure 1: actual and perceived. For example, a pro-Affordable Care Act (ACA) constituent might believe that his representative also voted for the ACA (perceived issue agreement), either correctly (they are also in actual issue agreement) or incorrectly (the representative in fact had voted against the ACA). Unlike most studies of accountability, our study measures these perceptions directly.

The purpose of Figure 1 is to distill our operationalization of accountability and estimation strategy. It does not exhaustively display alternative causal pathways, including the possibility of projection in which voters perceive to be in agreement because they approve of the representative (Lenz 2012), or the possibility that constituents infer party loyalty (Carson et al. 2010) or ideological extremity (Nyhan et al. 2012) from roll call votes. These mechanisms may be occurring simultaneously with issue accountability, perhaps with some voters but not others. Our contribution is to estimate one particular quantity - issue ac- 
countability as envisioned by the classical theory of representation — by controlling away such alternative explanations from our estimates. We focus on the dyadic relationship between a constituent and his representative and assume that, if a constituent can and does hold his representative accountable, he does so regardless of whether the legislator is pivotal.

This model of constituent perception is far from novel: It mirrors Figure 1 of "Constituency Influence in Congress" (Miller and Stokes 1963), which conceptualized how representatives made decisions based on their perceptions of their constituents' preferences. In fact, one goal of the present study is to provide a constituent's perspective of the sort of accountability studied in Miller and Stokes.

\section{Estimation Strategy}

We focus on estimating three components of issue accountability depicted in Figure 1 from observed data and survey experiments. Most studies of accountability estimate the effect of actual agreement on evaluations. We estimate this quantity through the reduced form equation, indexing constituents by $i \in\{1, \ldots, n\}$ :

$$
\text { Reduced Form: } \mathrm{Y}_{i}=\rho_{0}+\rho_{\mathrm{I}} \mathrm{Z}_{\mathrm{I} i}+\rho_{\mathrm{P}} \mathrm{Z}_{\mathrm{P} i}+\mathbf{X}_{i}^{\prime} \rho_{\mathrm{X}}+\varepsilon_{1 i}
$$

where $\mathrm{Y}_{i}$, following Figure 1, is constituent $i$ 's evaluation of his representative, $\mathrm{Z}_{\mathrm{I} i}$ is their actual agreement on issues, $\mathrm{Z}_{\mathrm{P} i}$ is their actual agreement on party affiliation, and $\mathbf{X}_{i}$ denotes a set of control variables we discuss later. A positive value of $\rho_{\mathrm{I}}$, interpreted causally, represents "Out of Step, Out of Office" (Canes-Wrone et al. 2002): when a representative takes a vote that is not in agreement with her constituent, the constituent reacts by lowering their propensity to vote to re-elect that incumbent. We refer to equation (1) as the reduced form anticipating our instrumental variable estimation strategy.

Although important, the reduced form does not describe how the constituent came to that evaluation. The first stage therefore asks whether the actual agreement implied by legislators' 
roll call votes shapes constituents' perceived agreement on those votes. Estimating this relationship from data corresponds to a linear regression:

$$
\text { First Stage: } \mathrm{A}_{\mathrm{I} i}=\alpha_{0}+\alpha_{\mathrm{I}} \mathrm{Z}_{\mathrm{I} i}+\alpha_{\mathrm{P}} \mathrm{Z}_{\mathrm{P} i}+\mathbf{X}_{i}^{\prime} \alpha_{\mathrm{X}}+\varepsilon_{2 i}
$$

where $\mathrm{A}_{\mathrm{I} i}$ refers to $i$ 's perceived agreement with their representative on the issues. A positive value of $\alpha_{\mathrm{I}}$, again interpreted causally, indicates that reality shapes perception: controlling for actual party agreement and other possible confounders $\left[\mathrm{Z}_{\mathrm{P} i}, \mathbf{X}_{i}\right]$, constituents form on the whole correct perceptions about their representative's votes in Congress.

The first stage then leads to the central question of issue accountability: to what extent do constituents act upon those perceptions, as measured by their evaluations (e.g., job approval or their propensity to re-elect her)?

$$
\text { Second Stage: } \mathrm{Y}_{i}=\beta_{0}+\beta_{\mathrm{I}} \mathrm{A}_{\mathrm{I} i}+\beta_{\mathrm{P}} \mathrm{A}_{\mathrm{P} i}+\mathbf{X}_{i}^{\prime} \beta_{\mathrm{x}}+\varepsilon_{3 i}
$$

One threat to inference that is new in interpreting the $\beta$ coefficients causally is projection, which we can formalize as the endogeneity of perceived agreement. For example, a respondent might have underlying trust in the representative, which both leads to higher job approval and also leads him to the belief that the representative probably agrees with him on key issues too. To remove such potential confounding we implement an instrumental variables strategy, instrumenting perception with actual agreement with equation (2) as suggested by Figure 1. If our instrumental variables specification is appropriate, a two stage least squares regression combining equations (2) and (3) will estimate the magnitude of issue accountability unconfounded by projection.

For the instrumental variables approach to produce unbiased estimates, three conditions must be met. First, the first stage outlined in equation (2) must be strong. We show in our results that this condition is easily met in our data. Second, the effect of the instrument on the outcome must flow exclusively through the variable being instrumented. Although this 
is an untestable assumption, we point out that it is a natural one in our setting given that constituents can only form evaluations based on what they perceive.

The third condition, exogeneity of the instrument conditional on controls, is the most difficult of the three to meet in our setting. The same sort of exogeneity condition is required for interpreting the reduced form and the first stage coefficients causally as well.

To achieve conditional exogeneity, we control for five types of well-known potential confounders in all our regressions. (i) Representative fixed effects accounts for any time-invariant and issue-invariant characteristics of each Member of Congress, such as party affiliation or personality that may induce spurious correlation across districts. (ii) Theories of partisan heuristics predict that many constituents infer positions only from associations with party labels, so we treat actual party agreement $\left(\mathrm{Z}_{\mathrm{P}}\right)$ as a control. Next, a member's voting patterns is surely correlated with her latent ideology, so we control for (iii) ideological agreement with the incumbent to account for the representative's residual voting pattern after accounting for the key votes of interest. For similar reasons we control for the (iv) ideological distance from the challenger in general election years, as proxied by constituents' placements of those candidates. Finally, we include (v) socio-demographic characteristics of the respondent that may shape evaluations and perceptions, including age, gender, race, education, and income.

In a "perfect" experiment, representative's actual rollcall votes would be randomized, exogeneity would be satisfied by design, and then analysts would only need to compare constituents' approval of a representative who voted 'yea' with approval among otherwise similar constituents of a representative who voted 'nay'. To approximate that impossible experiment and anticipating potential violations of conditional exogeneity, we conducted two survey experiments that randomize information about representative's votes. We hasten to note that any randomized control trial faces a limitation when testing theories of electoral accountability. Almost all field experiments assign constituents to hear about representative's real positions (e.g. Broockman and Butler 2017), and therefore induce variation in perceived agreement $\left(\mathrm{A}_{\mathrm{I}}\right)$ but not in actual agreement $\left(\mathrm{Z}_{\mathrm{I}}\right)$. The inferential strengths of observational 
and experimental approaches complement each other's weaknesses.

The final way we address potential violations to the exogeneity assumption is by applying sensitivity analyses. Recent statistical developments in this area provide a benchmark of how large the unobserved confounding must be for our main conclusions to reduce to null (Cinelli and Hazlett 2020). Put together, our experiments and sensitivity analyses indicate that constituents do react to information consistent with classical theories of accountability, and that any unobserved confounding in our observational analyses would have to be larger than the effect of copartisanship on the same outcome to flip our main findings.

\section{Data and Measurement}

To operationalize our measures we rely on the CCES from 2006 to 2018, covering the 109th Congress under the presidency of George W. Bush through the 115th Congress under the first two years of President Trump. A measure of constituent opinion on key votes is available for all CCES respondents, but measures of constituent's perceptions of those votes is only included in one or two team modules a year (Table A1). ${ }^{1}$ We therefore primarily use these respondents in the team module, and append information from the common content.

Each year's CCES polls important issues from Congress' agenda each year, identified by the Congressional Quarterly or the Washington Post Key Vote. Table A2 lists all of the issues on the CCES on which there were corresponding bills in Congress, and how the House and Senate dealt with that bill. In particular, we analyze 44 floor votes in the U.S. House of Representatives ${ }^{2}$ for which perception questions were asked. In the first three Congresses (2006 - 2010), both the House and the Senate usually took up key legislation. But during

1 Each team module and the Common Content are separately weighted to be representative of the national adult population.

2 Throughout this paper we focus on representation in the U.S. House. The U.S. Senate requires an even more complex analysis, owing to the multiple representatives per district and the possible effects of state size on representation. We leave that for future work. 
2013 and 2015, Republican congressional leaders put few substantive policies for a vote on the House floor, fighting the President to a stalemate over the budget resulting in a government shutdown which clogged the legislative agenda. Once the Republican party gained unified control in 2017, they passed more significant bills.

Representative behavior and constituent opinion are difficult to compare on the same scale. The CCES addresses this measurement challenge by presenting issues as a key vote that Congress is considering or is anticipated to consider, ${ }^{3}$ and describing the issue in concrete terms. These questions have been widely used in other work on representation (Bafumi and Herron 2010; Tausanovitch and Warshaw 2018; Ahler and Broockman 2018). ${ }^{4}$

After each congressional term we find the roll call vote corresponding to each of the questions, if a floor vote was held, and link the respondent's U.S. House representative's vote to that response for our measure of actual agreement. Our measure of perceived agreement is built from the interaction between a constituent's perception of their representative and their own preferences. An example of a short ${ }^{5}$ perception question comes from 2017:

"This year Congress considered several bills to repeal or change the Affordable Care Act. For each of the following bills we would like to know how you think your member of Congress voted and whether you support or oppose the bill.

3 The CCES is fielded in the fall of each year. The legislative calendar is such that for almost all questions, the rollcall vote has already occurred before respondents answer the CCES. 4 The benefits of this issue-by-issue approach are summarized well in Lax et al. (2019). Hill and Huber (2019) show that providing contextual information such as the party leader's positions moves respondent's reported preference towards those positions. We use the responses to our questions as a measure of preferences before such cues are made explicit.

5 Other bills were described more concretely, for example the Dodd-Frank Act was described as "Protects consumers against abusive lending, regulates high risk investments known as derivatives, and allow government to shut down failing financial institutions." All question wordings are available on the CCES Dataverse. 
"A Bill to repeal the Affordable Care Act, known as Obamacare.

"Do you support or oppose this bill?

Support

Oppose

"Do you think [Representative $]^{6}$ voted for or against a bill to Repeal Obamacare?7

For

Against

Not Sure

We then represent respondent $i$ 's Perceived Issue Agreement on issue $j \in\{1, \ldots, m\}$ as $\mathrm{A}_{\mathrm{I} i j}$ and assign it a value of 1 if respondent $i$ 's preference agrees with his perception of his representative's roll call vote on issue $j$ (i.e., for-for or against-against). If the respondent's preference is in disagreement with his belief (i.e., for-against, or against-for), then $\mathrm{A}_{\mathrm{I} i j}=$ -1 . And $\mathrm{A}_{\mathrm{I} i j}=0$ if the respondent either does not have a belief or does not express a preference on the issue. We then compute respondent $i$ 's Perceived Issue Agreement with his representative as the average across issues, i.e. $\mathrm{A}_{\mathrm{I} i}=\frac{1}{m} \sum_{j=1}^{m} \mathrm{~A}_{\mathrm{I} i j}$.

We code the rest of the variables similarly, from -1 to 1 to facilitate comparison. Perceived Party Agreement $\left(\mathrm{A}_{\mathrm{P} i}\right)$ is the party equivalent of Perceived Issue Agreement: It is 1 if respondent $i$ identifies himself as the same party as he perceives the representative to be (i.e., Republican-Republican, or Democrat-Democrat). It is -1 if he thinks the representa-

${ }^{6}$ The name of the representative is filled in with the respondent's U.S. House incumbent representative, without displaying their party affiliation.

${ }^{7}$ Several dozen unrelated questions are typically placed in between the first question (asked in the common content) and the second question (asked in the team modules) to minimize demand effects. 
tive is of the opposite party, and 0 if either the respondent is not sure of the party of his representative or he identifies as an Independent.

Actual Issue Agreement $\left(\mathrm{Z}_{\mathrm{I} i}\right)$ is the counterpart to perceived issue agreement, with the respondent's belief about the vote replaced by the representative's actual roll call vote. In other words, $\mathrm{Z}_{\mathrm{I} i j} \neq \mathrm{A}_{\mathrm{I} i j}$ indicates respondent $i$ 's perception of his representative's vote on issue $j$ is incorrect. Actual Party Agreement $\left(\mathrm{Z}_{\mathrm{P} i}\right)$ is the counterpart to perceived party agreement, with the respondents' perceptions of their representative's party replaced with their representative's actual party affiliation.

We measure evaluations of the representative $\mathrm{Y}_{i}$ by approval and vote. Approval of the current representative ranges from "Strongly Disapprove" to "Strongly Approve", rescaled from -1 to +1 with equal intervals. The CCES measures Vote Choice in general election years by asking who respondents intend to vote for, presenting candidates' name and party. The variable is 1 if the respondent intends to vote for the incumbent, -1 if voting for the challenger, and 0 if he does not plan to vote or is unsure. If an incumbent is not running for reelection, the observation is dropped from this analysis.

The control variable Actual Ideological Agreement is measured as the proximity between the representative's DW-NOMINATE score and the voter's ideological self-placement. This is an admittedly coarse measure because we do not jointly scale constituents and candidates. But Broockman (2016) highlights the challenges of scaling public opinion. And more importantly, our main task is to test models of accountability, in which voters evaluate incumbent legislators ex-post (Fearon 1999) — not to explore whether candidate choice is a function of spatial distance. Further details on operationalization are left to Appendix A.

Table 1 presents summary statistics for each of the variables. To substantively interpret these values, note that the mean of a variable that is coded $\{1,0,-1\}$ is the difference between the percent of the sample coded 1 and the percent coded -1 . For example, the mean value of vote choice is the percent of the sample who would vote for the representative minus the percent who would vote for the challenger. In other words, on average incumbents 
Table 1 - Descriptive Statistics

(a) Predictor Variables and their Instruments

\begin{tabular}{lccc}
\hline & Mean & $\begin{array}{c}\text { Standard } \\
\text { Deviation }\end{array}$ & Observations \\
\hline Perceived Issue Agreement & 0.090 & 0.590 & 51,115 \\
Perceived Party Agreement & 0.114 & 0.714 & 49,195 \\
Actual Issue Agreement & 0.101 & 0.662 & 51,172 \\
Actual Party Agreement & 0.119 & 0.788 & 47,664 \\
\hline
\end{tabular}

(b) Outcome Variables

\begin{tabular}{lccc}
\hline & Mean & $\begin{array}{c}\text { Standard } \\
\text { Deviation }\end{array}$ & Observations \\
\hline Job Approval & 0.066 & 0.711 & 45,600 \\
Vote Choice (for incumbent) & 0.230 & 0.844 & 25,984 \\
\hline
\end{tabular}

Note: All variables range from -1 to 1 .

enjoy a 23 point vote margin from their constituents. Panel (a) shows that representatives have a 10 point net agreement on all four measures. In other words, House representatives are 10 percentage points more likely to vote on the same side of their constituent, in terms of roll call vote and party, in perception as well as in reality.

\section{Effects of Actual Roll Call Votes on Evaluations}

Our model of accountability (Figure 1) is a three-component process, tracing the votes representatives make to constituent's perceptions and evaluations. We examine the reduced form effect of actual agreement on downstream evaluations first, because the finding is a familiar one to the literature and it sets the stage for the two remaining psychological mechanisms.

Actual Issue Agreement appears to have a strong, consistent effect on people's evaluations of their representatives. Table 2 presents estimates from the regression in equation (1). These regressions include the controls previously discussed - representative fixed effects, ideological agreement, ideological distance from the challenger, and demographic variables. Standard errors are clustered at the representative level to account for correlated errors. The coefficient on Actual Issue Agreement in predicting approval is 0.23. That means a person 
Table 2 - Actual Agreement and Evaluations (Reduced Form)

\begin{tabular}{|c|c|c|c|c|c|}
\hline & \multicolumn{5}{|c|}{ Outcome: Approval } \\
\hline & All Years & $\begin{array}{l}\text { Bush 2nd } \\
(2006-2008)\end{array}$ & $\begin{array}{l}\text { Obama 1st } \\
(2009-2012)\end{array}$ & $\begin{array}{l}\text { Obama 2nd } \\
(2013-2016)\end{array}$ & $\begin{array}{c}\text { Trump } \\
(2017-2018)\end{array}$ \\
\hline Actual Issue Agreement & $\begin{array}{c}0.23 \\
(0.006)\end{array}$ & $\begin{array}{c}0.33 \\
(0.01)\end{array}$ & $\begin{array}{c}0.29 \\
(0.008)\end{array}$ & $\begin{array}{c}0.06 \\
(0.01)\end{array}$ & $\begin{array}{c}0.23 \\
(0.03)\end{array}$ \\
\hline Actual Party Agreement & $\begin{array}{c}0.22 \\
(0.006)\end{array}$ & $\begin{array}{c}0.11 \\
(0.01)\end{array}$ & $\begin{array}{c}0.23 \\
(0.007)\end{array}$ & $\begin{array}{c}0.23 \\
(0.01)\end{array}$ & $\begin{array}{c}0.22 \\
(0.02)\end{array}$ \\
\hline Average of Outcome & 0.07 & 0.04 & 0.08 & 0.05 & 0.06 \\
\hline R-squared & 0.39 & 0.36 & 0.47 & 0.32 & 0.46 \\
\hline Clusters & 847 & 482 & 529 & 498 & 434 \\
\hline \multirow[t]{3}{*}{ Observations } & 42,559 & 10,010 & 23,675 & 6,286 & 2,588 \\
\hline & \multicolumn{5}{|c|}{ Outcome: Vote Choice } \\
\hline & $\begin{array}{l}\text { All Even } \\
\text { Years }\end{array}$ & $\begin{array}{l}\text { Bush 2nd } \\
(2006,2008)\end{array}$ & $\begin{array}{l}\text { Obama 1st } \\
(2010,2012)\end{array}$ & $\begin{array}{l}\text { Obama 2nd } \\
(2014,2016)\end{array}$ & $\begin{array}{l}\text { Trump } \\
(2018)\end{array}$ \\
\hline Actual Issue Agreement & $\begin{array}{c}0.20 \\
(0.010)\end{array}$ & $\begin{array}{c}0.28 \\
(0.04)\end{array}$ & $\begin{array}{c}0.24 \\
(0.01)\end{array}$ & $\begin{array}{c}0.08 \\
(0.02)\end{array}$ & $\begin{array}{c}0.30 \\
(0.04)\end{array}$ \\
\hline Actual Party Agreement & $\begin{array}{c}0.35 \\
(0.01)\end{array}$ & $\begin{array}{c}0.35 \\
(0.03)\end{array}$ & $\begin{array}{c}0.30 \\
(0.01)\end{array}$ & $\begin{array}{c}0.49 \\
(0.02)\end{array}$ & $\begin{array}{c}0.45 \\
(0.04)\end{array}$ \\
\hline Average of Outcome & 0.23 & 0.24 & 0.24 & 0.21 & 0.19 \\
\hline R-squared & 0.48 & 0.63 & 0.48 & 0.53 & 0.67 \\
\hline Clusters & 786 & 411 & 484 & 445 & 368 \\
\hline Observations & 24,051 & 1,801 & 16,946 & 3,749 & 1,555 \\
\hline
\end{tabular}

Note: Estimate of the reduced form models in equation (1). Standard errors clustered by representative in parenthesis, and control variables not shown.

whose own preferences on issues are in complete agreement with their representatives' roll call votes on those issues is 11 percentage points more likely to approve of the representative than another constituent of the same representative, of the same party, and of the same ideology, but agrees with only half of the issues. The coefficient on Actual Issue Agreement in predicting vote choice is 0.20 . That means the incumbent's share of the votes is 10 points higher among constituents who are in complete agreement on issues than, again, another constituent with the same observable characteristics but is in agreement with only half of the issues. These are substantively large effect sizes, given the strict match on covariates we are enforcing with the controls in the regression.

Actual Party Agreement is also, unsurprisingly, associated with strong evaluations. The 
effect of Actual Party Agreement is 0.22 on approval and 0.35 on vote choice. Party and issues have comparable effects on approval, but party agreement controlling for issue agreement has a larger effect on vote choice.

The threat to inference remaining after Table 2 is the lingering suspicion of omitted variable bias. We take the sensitivity analysis approach by Cinelli and Hazlett (2020) to address this risk, asking how strong an unobservable omitted variable would have to be to render the coefficient on Actual Issue Agreement null. In Appendix E, we find that an unobserved confounder would have to be more than twice as strong as co-partisanship to explain away our results in the approval regression, and about 1.5 times as strong in the vote choice regression. Given the predominance of partisanship in vote choice, it is hard to imagine such a variable that is not already in our list of controls.

The conclusions we can draw from these findings are similar to aggregate studies which measure agreement in terms of rollcall scores and presidential vote, party loyalty, and individual-level studies that measure ideological distance. Where our results part from these studies is that we suggest that specific votes on key issues may move evaluations, even holding party or ideological congruence constant. But this reduced form effect is incomplete. It is unclear from this quantity alone how or if constituents perceive issue agreement and whether they act on it, which we turn to next.

\section{ReAlity AND Perception}

The first requirement for accountability is accurate perception of actual agreement. Issuevoters who are nevertheless misinformed about how their representative stands on those issues leads to what Bartels (2008) called "unenlightened self-interest" (p.150). Survey researchers have long documented that citizens appear to have thin factual knowledge about Congress (Delli Carpini and Keeter 1997; Fowler and Margolis 2014). Other scholars argue that the electorate reasons, even with incomplete or partial information, to draw fairly accurate inferences about politics, such as the positions their representatives take (Lupia 
and McCubbins 1998). Our measure of perceived and actual agreement are well-suited to adjudicate these claims.

\section{Correct Perceptions}

Twice as many respondents in the CCES data hold correct beliefs about how their representatives voted as hold incorrect beliefs. For the average issue, 43 percent of voters perceive correctly, 42 percent are not sure, and 19 percent have an incorrect perception. 73 percent can name the correct party affiliation, 21 percent are not sure, and 6 percent are incorrect. Table B1 in the Appendix presents these numbers for each issue and for party.

Further, constituents who are more educated, express higher interest in the news, and are higher-income are significantly more likely to have correct perceptions. And constituents of extremist representatives are also more likely to have correct perceptions of how their member voted compared to constituents with similar individual demographics but in a district represented by a more moderate representative (also see Dancey and Sheagley 2016). These patterns are borne out by a Heckman selection model which estimates first the likelihood of a constituent to make a guess, and second the likelihood that the guess is correct conditional on making a response (Appendix C). All together, the factors that shape correct perceptions for issues fall squarely into theories of communication that find the receptivity of the

respondent (in this case, the constituent) and the strength of the signaler (in this case, the representative) to be important determinants of perceptions.

One possible concern with our measurement of perception is that respondents might have looked up the answers while taking the online survey. In Appendix $\mathrm{C}$ we provide evidence showing this is unlikely. The CCES tracks how many seconds each respondent spent on each page. Respondents take about as long answering the perception question as they do answering other questions of the same length and format, and respondents who take longer to answer are actually less likely to provide correct answers. 
Figure 2 - Does Perceived Agreement Reflect Actual Agreement?

All Repsondents

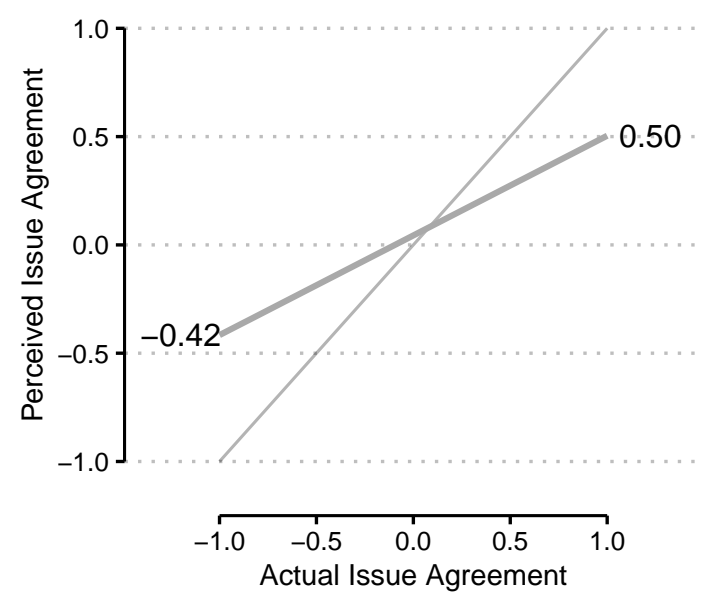

By Perceived Party Agreement

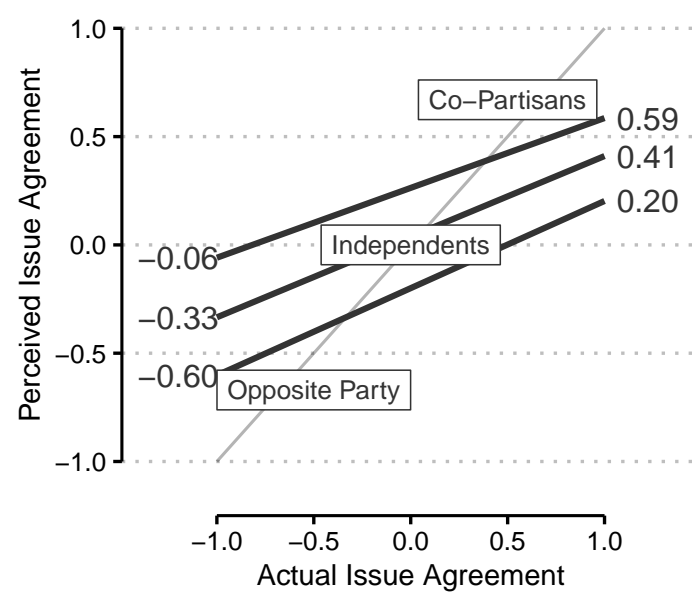

Note: Lines show OLS best fit lines and numbers show predicted value at endpoints. The 45 degree line indicates perfect correspondence.

\section{Actual Agreement and Perceived Agreement}

Modeling the relationship between perceived and actual issue agreement illustrates the coexistence of partisan bias and accurate learning more clearly. The left panel of Figure 2 shows that constituents who in fact disagrees with their representative on all the issues asked in the CCES also perceive to be disagreement: an average of -0.42 on a -1 to 1 scale. Those who agree with their member on all bills perceive an agreement of 0.50 . The resulting slope of 0.46 reflects how perception does track reality on average, but not perfectly (which would result in a slope of 1). The attenuation is explained by both incorrect perceptions and "not sure" responses.

This relationship between reality and perception might be spurious, however, driven by the composition of partisan loyalists who are oblivious to actual issues. The right panel controls for the perceived party agreement and lends support to both stories: perception is both biased in terms of party, but it is also responsive to actual agreement. Among perceived co-partisans, those who are in-truth in complete disagreement $(-1)$ on the issues perceive an agreement of -0.06 on average. If they were perfect perceivers, the score would 
Table 3 - Actual Agreement and Perceived Agreement (First Stage)

\begin{tabular}{lcc}
\hline & $\begin{array}{c}\text { Outcome: } \\
\text { Perceived } \\
\text { Issue } \\
\text { Agreement }\end{array}$ & $\begin{array}{c}\text { Outcome: } \\
\text { Perceived } \\
\text { Party } \\
\text { Agreement }\end{array}$ \\
\hline Actual Issue Agreement & 0.34 & 0.05 \\
Actual Party Agreement & $(0.006)$ & $(0.004)$ \\
Actual Ideological Agreement & 0.10 & 0.63 \\
& $(0.004)$ & $(0.006)$ \\
\hline Average of Outcome & 0.30 & 0.14 \\
Std. Dev. of Outcome & $0.008)$ & $(0.007)$ \\
R-squared & 0.59 & 0.12 \\
F-test for Weak Instruments & 0.36 & 0.71 \\
Clusters & 2,116 & 0.60 \\
Observations & 848 & 848 \\
\hline Clostered Stan & 46,574 & 46,585 \\
\hline
\end{tabular}

Clustered Standard Errors by Representative.

Note: Each column is a OLS regression. Controls, representative fixed effects, and year fixed effects not shown. Clustered standard errors by representative.

be at -1 . Similarly, perceived opposite-partisans who are in-truth in complete agreement with the member on the specific issues have a net perceived agreement of only 0.20 . The slopes of all three groups are attenuated towards zero but are still positive and significantly distinguishable from a flat line. It does not appear that the correlation is completely driven by partisan biases.

The first stage of equation (2) in Table 3 further confirm that it is the facts of the roll call vote, rather than party heuristics, that predominantly shape the perception of votes. The coefficient on Actual Issue Agreement in predicting Perceived Issue Agreement is 0.34, meaning that if a constituent supports a bill and is represented by a member who voted for that bill, he is 34 percentage points more likely to believe they are in agreement with the legislator on that bill (compared to if the representative had voted against the bill). Sensitivity analyses in Appendix E show how unlikely it is that this relationship is confounded by unobserved variables. Even if there were an omitted confounder that is as strong as Actual Party Agreement, the coefficient estimate would only drop to 0.30 . 
Party does appear to serve as a heuristic in shaping beliefs about representative's legislative decisions. However, the coefficient sizes suggest that it is of secondary importance: the effect of Actual Issue Agreement is three times larger than the effect of Actual Party Agreement on how voters perceive issue agreement. And a parallel pattern emerges with constituent's perceptions of party agreement. In the second column of Table 3, the coefficient on Actual Party Agreement in predicting Perceived Party Agreement is 0.63.

There is a symmetry, then, between the two regressions in Table 3: constituents learn about issues more from issues than from party, and learn about party more from party than from issues. In Appendix A we provide estimates by issue and find some variation over time which, in Appendix D, we in part attribute to the Congressional agenda.

On the whole, the public's perceptions are rooted in the reality of the decisions representatives make. ${ }^{8}$ There is evidence of uncertainty and copartisan misperception, but Table 3 shows these to be second-order. The typical person's understanding of how their representative voted on key legislation is, on balance, a fairly accurate reflection of their legislator's actual behavior. The question we turn to next is how much constituents use that information to hold legislators accountable.

\section{Perception AND Evaluation}

The reduced form indicates that there are downstream consequences to a representative's votes, and the first stage indicates that constituent's perceptions about those positions are noisy and biased, but on average track actual positions. This sets the stage for the third and final component of electoral accountability in Figure 1: how constituents translate perceived agreement to the evaluations of their representative. We use three approaches to isolate this causal quantity.

${ }^{8}$ In the context of our instrumental variables strategy, this means that our instruments are strong. The $F$-statistic is over 2,000 instrumenting for perceived issue agreement. 
Figure 3 - Differences in Evaluation by Perceived Agreement

(a)

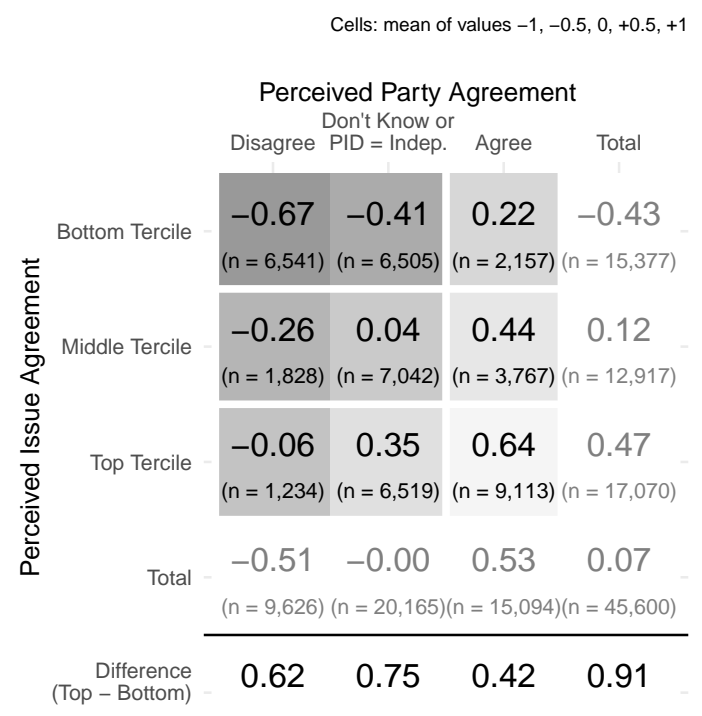

(b)

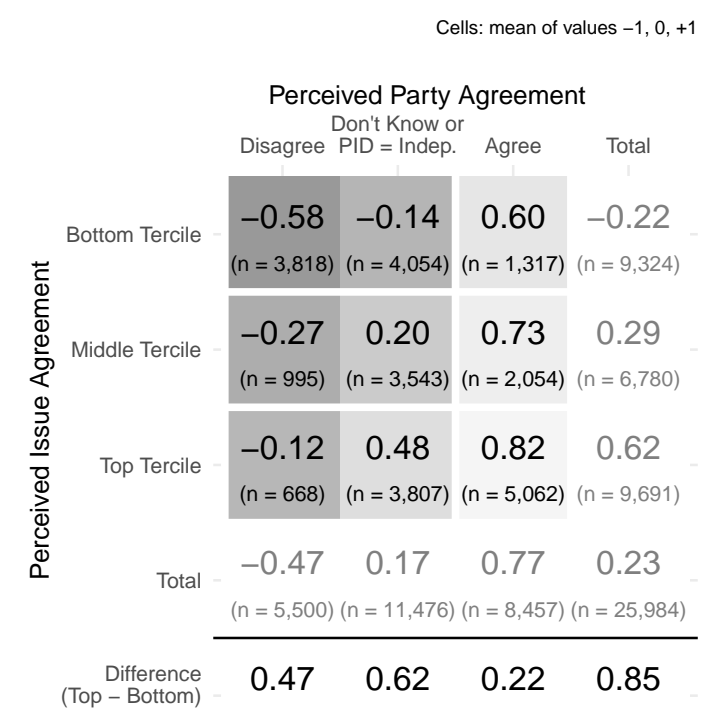

Note: Cells are averages of (a) approval and (b) vote for the representative.

\section{Difference in Conditional Means}

We first sketch out the relationship with conditional difference in means. Figure 3 displays weighted averages of approval and vote choice by subsets of perceived agreement. Recall that our outcome variables range from -1 to 1 , so the average of the vote choice variable is equivalent to the electoral margin of the incumbent. The average of approval is similarly interpreted as the net approval, percent approval minus percent disapproval. Consider first the differences in row averages in panel (a). Constituents who perceive low levels of issue agreement with their representatives, displayed in the top row, express a net approval rating of -0.43 , but those who see themselves in agreement with their representatives' roll call votes have a net approval of 0.47 .

These differences due to issue agreement are not explained away by partisan agreement. The row below the solid line of Figure 3 shows the difference in outcomes between the top and bottom terciles of issue agreement, within each level of party agreement. Take incumbent vote choice in panel (b). Among people who believe they are the same party as the incumbent 
(the third column), the difference between high and low issue agreement is 22 points in vote margin. Among people who believe they are the opposite party as their representatives, the same difference is 47 points in vote margin. And among independents and those who did not know the party of their representatives, the improvement is 62 points.

We hold constant more characteristics of the representative, the constituent, the issue at stake, and the congressional district by estimating equation (3). These estimates in Appendix $B$ show that a one-unit increase in perceived issue agreement on a scale of -1 to +1 is associated with an increase in the respondent's net job approval of 19 percentage points, holding constant other correlates of issue agreement such as perceived party agreement and perceived ideological agreement. For vote choice, an improvement in perceived issue agreement from the middle of the scale to complete issue agreement is associated with an increase in the respondent's likelihood of voting for that incumbent by about 11 percentage points. These indicate that accountability does exist, smaller than the simple difference-in-means suggested by Figure 3 but on the same order of magnitude.

\section{Instrumental Variable Estimates}

The difference-in-means approach may overstate the causal effect of perceived issue and party agreement on evaluations if there are unobserved confounders that are correlated with perceived agreement and correlated with evaluations. To correct for these statistical biases, we implemented our instrumental variable (IV) estimator shown in Figure 1 and equations (2) and (3).

We see substantively large direct effects of issues on vote choice in every Congress studied, with some variation over time. Table 4 summarizes our key results (See also Appendix B for issue-specific estimates). We start with the first column that uses the data from all years. The IV coefficient on Perceived Issue Agreement predicting approval is 0.64 and the coefficient on predicting vote choice is 0.58 . Because the standard deviation of Perceived Issue Agreement is about 0.60 (Table 1), this indicates that a one-standard deviation improvement 
Table 4 - Perceived Agreement and Evaluations (Instrumental Variables)

\begin{tabular}{lccccc}
\hline & \multicolumn{5}{c}{ Outcome: Approval } \\
\cline { 2 - 6 } & All Years & $\begin{array}{c}\text { Bush 2nd } \\
(2006-2008)\end{array}$ & $\begin{array}{c}\text { Obama 1st } \\
(2009-2012)\end{array}$ & $\begin{array}{c}\text { Obama 2nd } \\
(2013-2016)\end{array}$ & $\begin{array}{c}\text { Trump } \\
(2017-2018)\end{array}$ \\
\hline Perceived Issue Agreement & 0.64 & 0.70 & 0.73 & 0.36 & 0.60 \\
& $(0.02)$ & $(0.03)$ & $(0.02)$ & $(0.08)$ & $(0.06)$ \\
Perceived Party Agreement & 0.22 & 0.08 & 0.23 & 0.34 & 0.28 \\
& $(0.009)$ & $(0.02)$ & $(0.01)$ & $(0.02)$ & $(0.03)$ \\
\hline Average of Outcome & 0.07 & 0.04 & 0.08 & 0.05 & 0.06 \\
Clusters & 847 & 482 & 529 & 498 & 434 \\
Observations & 42,417 & 9,999 & 23,625 & 6,205 & 2,588 \\
\hline & \multicolumn{5}{c}{ Outcome: Vote Choice } \\
\hline & All Even & Bush 2nd & Obama 1st & Obama 2nd & Trump \\
\cline { 2 - 7 } & Years & $(2006,2008)$ & $(2010,2012)$ & $(2014,2016)$ & $(2018)$ \\
\hline Perceived Issue Agreement & 0.58 & 0.97 & 0.60 & 0.48 & 0.78 \\
Perceived Party Agreement & $(0.03)$ & $(0.1)$ & $(0.04)$ & $(0.2)$ & $(0.1)$ \\
& 0.43 & 0.42 & 0.33 & 0.87 & 0.69 \\
& $(0.02)$ & $(0.05)$ & $(0.02)$ & $(0.06)$ & $(0.07)$ \\
\hline Average of Outcome & 0.23 & 0.24 & 0.24 & 0.22 & 0.19 \\
Clusters & 786 & 411 & 484 & 445 & 368 \\
Observations & 23,949 & 1,799 & 16,915 & 3,680 & 1,555 \\
\hline
\end{tabular}

Note: Each column is an instrumental variables regression. Controls, representative fixed effects, and year fixed effects not shown. Clustered standard errors by representative.

in a constituent's Perceived Issue Agreement improves net approval or the vote margin of the incumbent by about 35 percentage points.

We further explore the possibility that the degree of issue voting varies across types of people, types of issues, and the context of specific roll call votes. Details of those analyses are in Appendix D. First, the estimates may vary with the salience of the issue to the public. All of these issues were salient in the sense of being key votes in Congress that made it to a floor vote. Nonetheless, some of the issues, especially health care, were routinely at the top of the legislative agenda for both parties. We divided the issues as highly salient and less salient, and found that the estimates were quite similar.

Second, we examined the heterogeneity of effects due to strategic roll call voting. It may 
be the case that voters reward and punish legislators more sharply when the legislators' votes are pivotal to the passage of legislation (Snyder and Groseclose 2000). We found no evidence that voters responded more to their legislator being pivotal on close votes than to other contexts. Nor did we find evidence that abstention insulates legislators by creating ambiguity (Arnold 1990).

Finally, we examined whether the effect of issues only exists among high interest voters. We divided the sample by level of political interest (following Bartels 1996) and found no consistent differences in issue voting: The coefficients on perceived agreement on issues were similar for high, medium, and low levels of interest. Higher interest voters were, however, more ideological and less partisan than low interest voters. This pattern suggests an important way in which issue voting is distinct from ideological and partisan voting.

The interpretation of the IV estimate also deserves more nuance. There are two ways to interpret the IV coefficient — one from an omitted variable perspective and the other as a local average treatment effect. In the former, the IV coefficient represents the average effect of the treatment variable (in this case, perceived issue agreement) after controlling away attenuation biases due to measurement error and unobserved confounding. In other words, the IV estimate is an improved version of the OLS estimate.

If the effect among respondents that change their perceived agreement in response to actual agreement is different than the effect among other groups, however, the IV coefficient identifies the average treatment effect among the former group, also known as compliers. ${ }^{9}$ On the one hand, this means that the IV estimates are less generalizable to an average effect. Fortunately, the nature of our instrument means that the compliers are a theoretically important group in their own right. These are constituents who, by definition, respond to changes in reality. Our large IV estimates interpreted as a local average treatment effect

9 These do not include constituents who, upon an increase in actual agreement decrease their perceived agreement, or vice versa. Such individuals would be defiers in the IV context and must be assumed away. 
therefore suggests that this perceptive subset of the electorate enforces a strong degree of accountability.

We do not deny the existence of projection. For example, one could imagine that prior approval (independent of actual issue agreement) affects perceived agreement — the reverse of our causal claim. If this is correlated with current approval, it would induce a correlation between perceived agreement and current approval. Still, what our IV results show is that another causal pathway, perhaps together with some partisan projection, exists: one in which actual agreement flows through perceived agreement such that constituents hold their representatives accountable.

\section{Experimental Evidence of the Causal Connection}

Our third approach to measuring the effect of perceived issue agreement on evaluation addresses the concern that the IV estimates may suffer from a violation in the exogeneity condition. We conducted two randomized experiments, one during the Democratic Congress under President Obama and another during the Republican Congress under President Trump. Two of our CCES modules contained experiments that selectively provided respondents with information about their representatives.

The 2009 study ( $n=5,700$ ) provided correct information to randomly chosen subsets of respondents and no information to others. One type of information regarded roll call votes. Respondents were told how their House representatives actually voted on two randomly chosen votes. The possible votes were the State Children's Health Insurance Program, the American Reinvestment and Recovery Act, the American Clean Energy and Security Act, and the Patient Protection and Affordable Care Act. An additional type of information was party: half of the sample was randomly chosen to be told the correct party affiliation of their representative and half were told no party information.

The 2018 study $(n=2,000)$ provided respondents with randomly determined information about four roll call votes. The study randomly assigned a Yes or No vote to the representative 
on four votes separately, regardless of whether that information was correct or incorrect. The bills were the 2018 Bipartisan Budget Act, the Tax Cuts and Jobs Act of 2017, the Mobilizing Against Sanctuary Cities Act, and the American Health Care Act which partially repealed the ACA. There was no party treatment in this study. To limit the risks associated with deception, all participants were debriefed shortly after and informed that the information they were provided was randomly chosen and was not a reflection of how their member of Congress actually voted on those issues.

To make estimates comparable with our observational analyses, we coded the issue treatment variables as 1 if the respondent had a preference that in fact agreed with the experimentally provided information about the representative's roll call vote, -1 if the respondent in fact disagreed with the provided information, and 0 if no information on that issue was provided. We coded the party treatment similarly, with 1 indicating treatment providing co-partisan information and -1 indicating treatment providing out-partisan information. We then computed the sum of the agreement measures for the different roll call votes divided by the number of treated roll call votes. Because our treatment variable includes non-randomized preferences, we control for pre-treatment Perceived Issue Agreement, pretreatment Perceived Party Agreement, the baseline measure of approval, and demographic variables when estimating treatment effects.

These experiments are meant to confirm the causal inferences from the main IV estimation strategy. Experiments have the advantage that, by design, whether the respondent received the information in the treatments is independent of any other factor. Experiments, of course, have their limitations. For example, we do not change how legislators actually voted, but only offer information to respondents. These are messages that respondents may accept or reject. The 2018 experiment may also be limited in external validity because it presents off-equilibrium signals, counterfactual votes that representatives chose not to cast. Such counterfactuals strength inferences about causality, but may weaken effects.

Both the issue and party treatments moved approval by 7 to 10 percentage points. The 
Table 5 - Experimental Effects of Issue Agreement

(a) 2009 Study

\begin{tabular}{|c|c|c|c|c|}
\hline & \multirow[t]{2}{*}{ All } & \multicolumn{3}{|c|}{ Subsets } \\
\hline & & No Prior & Some Wrong & All Correct \\
\hline Vote information treatment (in agreement) & $\begin{array}{c}0.10 \\
(0.01)\end{array}$ & $\begin{array}{c}0.08 \\
(0.02)\end{array}$ & $\begin{array}{c}0.11 \\
(0.02)\end{array}$ & $\begin{array}{c}0.01 \\
(0.03)\end{array}$ \\
\hline Party information treatment (in agreement) & $\begin{array}{c}0.07 \\
(0.01)\end{array}$ & $\begin{array}{c}0.12 \\
(0.02)\end{array}$ & $\begin{array}{c}0.05 \\
(0.02)\end{array}$ & $\begin{array}{c}0.03 \\
(0.02)\end{array}$ \\
\hline Average Outcome in Control & 0.04 & 0.00 & 0.08 & 0.02 \\
\hline Proportion High News Interest & 0.57 & 0.27 & 0.59 & 0.79 \\
\hline R-squared & 0.56 & 0.25 & 0.49 & 0.76 \\
\hline Observations & 4,863 & 1,409 & 1,626 & 1,828 \\
\hline
\end{tabular}

(b) 2018 Study

\begin{tabular}{|c|c|c|c|c|}
\hline & \multirow[t]{2}{*}{ All } & \multicolumn{3}{|c|}{ Subsets } \\
\hline & & No Prior & Some Wrong & All Correct \\
\hline Vote information treatment (in agreement) & $\begin{array}{c}0.08 \\
(0.02)\end{array}$ & $\begin{array}{c}0.08 \\
(0.06)\end{array}$ & $\begin{array}{c}0.08 \\
(0.03)\end{array}$ & $\begin{array}{c}0.11 \\
(0.07)\end{array}$ \\
\hline Average Outcome in Control & 0.03 & 0.01 & 0.10 & -0.23 \\
\hline Proportion High News Interest & 0.51 & 0.18 & 0.52 & 0.73 \\
\hline R-squared & 0.62 & 0.35 & 0.59 & 0.79 \\
\hline Observations & 1,947 & 284 & 1,348 & 315 \\
\hline
\end{tabular}

Note: Each column is an OLS regression where the outcome is approval. Pre-treatment controls not shown. Robust standard errors in parentheses.

first column in each panel of Table 5 presents the treatment effects for all respondents. The coefficients on the issue treatments are 0.10 in 2009 and 0.08 in 2018, and both are statistically distinguishable from $0(p<0.01)$. The coefficient on the party information treatment is of similar magnitude.

The effect of additional information should depend on voter's prior beliefs. We therefore divided the sample into subgroups of prior levels of completeness and correctness of beliefs. One subset did not have any belief about how their representatives voted on any votes; the second had incomplete and incorrect prior beliefs on some votes; and a third had correct prior beliefs on all votes. In the 2009 experiment, the information provided is correct so only the last group would not have received new information. In the 2018 experiment the information treatment is orthogonal to prior beliefs so all groups are equally treated. 
Our results are consistent with Bayesian updating. Respondents who had correct prior beliefs exhibited no statistically significant increase in approval in response to confirmatory information in the 2009 experiment. We also took the subset of 2018 respondents who had correct prior beliefs and estimated separate effects among those assigned correct information and those assigned incorrect information. The effect was concentrated among the latter (Appendix B).

Three implications of these experiments deserve emphasis. First, the experiments reaffirm the findings of issue accountability from the observational and instrumental variables. As Bullock (2011) found with a similar design to our 2009 experiment, people use information about roll call votes, when it is available, to evaluate their legislators. Second, people value the roll call vote information and party labels about equally in updating their evaluations of their representatives. Third, the subgroup comparisons confirm that our findings reflect real beliefs instead of random guessing.

\section{Reconciling Individual Versus Aggregate EfFects}

Our estimates indicate that the effect of a one standard deviation increase in perceived issue agreement is approximately 35 percentage points on an individual's likelihood of voting to re-elect the incumbent. That is in line with existing estimates from surveys, but much larger than estimates using aggregate election data. Canes-Wrone et al. (2002) estimate that a one standard deviation change in the rollcall score of the legislator to change their vote share by 1 to 3 percentage points or less (see also Bonica and Cox 2018). Tausanovitch and Warshaw (2018) reasonably ask why the individual and aggregate estimates in this literature differ.

The answer lies in aggregation. It is well known that analyses of correlations among aggregates suffer from the ecological fallacy, and use of proxy variables, such as use of presidential vote to measure constituents' preferences, introduces measurement error. Even setting aside these measurement problems, there are two first-order consequences of aggregation.

First, aggregation cancels out individual-level effects of opposing signs. If 100 percent of 


\section{Figure 4 - Consequences of Aggregation for Representation}

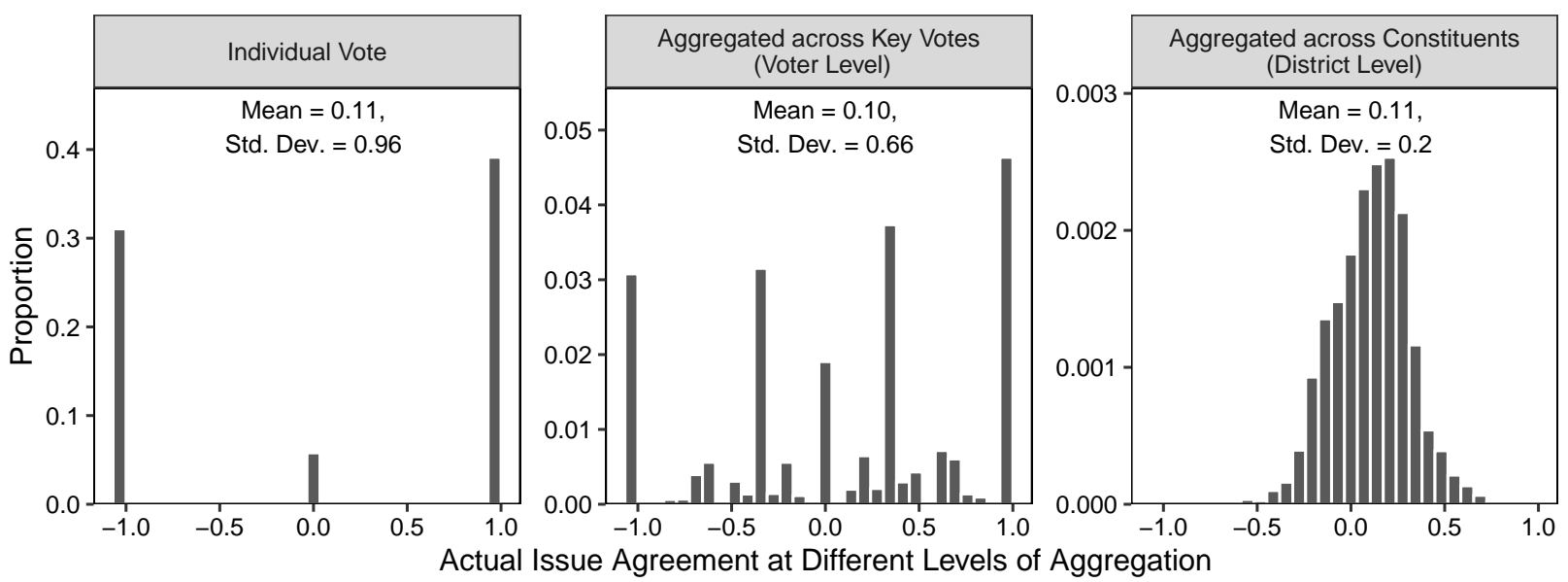

Note: Panels show the distribution of Actual Issue Agreement at the individual-level (left), the constituent-level (center) and the district-level (right).

constituents in a district support a bill, then, our estimates (Table 2) would suggest that a legislator can expect to see her voteshare increase by 20 percentage points if she votes for the bill instead of voting against it. But constituencies are never completely for or against a bill. On the typical CCES issue, a congressional district's constituents are split 60-40. In that case, the representative will increase her standing among the 60 percent of people who support the bill by 20 percentage points, but will simultaneously lose 40 percent of her constituents by the same magnitude. The net gain is only 4 percentage points in vote margin. The average actual issue agreement in our data at the individual-level is 0.10 (Table 1), which translates into 55 percent in agreement and 45 percent in disagreement. Therefore even assuming that the effect of a rollcall vote on an individual constituent's vote choice is 20 points, its contribution to vote share is only 2 points.

The scale of comparison is also smaller at the aggregate level. Typically, studies report the effect of a one standard deviation unit change in agreement on vote or approval. But the variation in the mean of a variable is necessarily smaller than the variation in the variable itself. Figure 4 illustrates this using the CCES, showing the distributions of Actual Issue Agreement measured at three levels. The standard deviation of Actual Issue Agreement 
at the individual level is 0.66 , while the standard deviation of its district-level counterpart is only 0.21 . The two distributions have the same mean but that similarity masks stark differences in scale. Hence, the effect of a one standard deviation change in issue agreement at the individual level is 13 percentage points (i.e., $0.66 \times 0.20$ ), but the effect of a onestandard deviation change in issue agreement at the district level is only 4 percentage points in vote margin (i.e., $0.21 \times 0.20$ ), or a 2 percentage point change in vote share.

The aggregate effects of issue congruence implied by the individual level estimates are on the same order as those estimated by researchers using aggregate data, even setting aside potential aggregation and measurement biases with those analyses. Put another way, small aggregate differences can still reflect strong issue voting at the individual-level.

\section{Conclusion}

This study has sought to advance the longstanding debate on electoral accountability by bringing extensive data on constituent knowledge and issue voting, combining multiple estimation strategies, and providing explanations to reconcile seemingly inconsistent findings. The classical theory of representation posits that constituents pay attention to and care about the policy decisions their representatives make. V.O. Key (1966), examining party switching between 1936 to 1960, argued that voters are "moved by concern about central and relevant questions of public policy" (p.8). Many others have openly challenged the tenets of the classical theory. Warren Miller and Donald Stokes (1963), examining the 1958 National Election Study, reached the conclusion that "given the limited information the average voter carries to the polls, the public might be thought incompetent to perform any task of appraisal" (p.53).

Twelve years of data across various political contexts demonstrate that the American electorate approximates the classical ideal in two essential respects. First, while the public is somewhat biased towards copartisan representatives, on the whole it sees Congress correctly. Second, constituents hold their representatives accountable for their votes on key legislative 
decisions. The typical constituent expresses considerably higher support for their congressional representatives when she or he sees that the representative has voted the way the constituent would have. Over twenty years ago Lupia and McCubbins (1998) asked whether "citizens can know what they need to know." Our findings on electoral accountability for key legislative decisions answer that question in the affirmative.

In the present political context, these findings are particularly striking. Against a background of party polarization in Congress, one might expect that the electorate has abandoned their own preferences on issues and, instead, blindly taken sides with one party. The evidence mustered here shows that voters can punish representatives with whom they disagree on legislative decisions, even if the representative is a copartisan. The effects of issues are approximately as large as the effects of party on constituents' evaluations. This contrasts starkly with theories that begin with the claim that most voters are largely ignorant about legislative decisions and thus conclude that constituents must rely on elites and party labels for representation (Bawn et al. 2012). We are not arguing that elite capture does not occur. Rather, we suggest that theories of representational failure cannot rely on the premise that individual voters are unable to hold legislators accountable on issues.

Our findings also help reconcile two observations. On the one hand, individual constituents respond strongly to their legislators' roll call votes. But on the other hand, aggregate voteshares are only modestly correlated with legislators' roll call voting records. This is a result of aggregation. Many legislative districts are fairly evenly split on key legislation. A legislator may vote with the majority of her district and get the support of 55 percent of her constituents, but lose the support of the remaining 45 percent. Those with whom the legislator sides care deeply about the issue, as do those opposed to the legislator's vote. But, in the aggregate the net effect is modest because much of the support and opposition for the bill cancels out. Aggregate correlations should not be taken as measures of the true degree to which individuals care about or vote on the issues. By the same token, in extremely competitive districts, representatives have a difficult time satisfying the majority of the voters 
back home.

In the end, were Miller and Stokes wrong? No, they simply did not have a powerful enough microscope. Advances in survey methodology and technology have made it possible to measure with greater accuracy and statistical power how individual voters see and respond to their representatives' policy decisions. The portrait that emerges is not an inattentive and uncaring electorate; nor is it a hyper-attentive, hyper-rational electorate. Rather, the electorate on the whole is sufficiently attentive and sufficiently motivated by public policy to exert electoral control, albeit imperfectly, as envisioned by the classical theory of representation. 


\section{REFERENCES}

Ahler, Douglas and David E. Broockman (2018). "The Delegate Paradox: Why Polarized Politicians Can Represent Citizens Best". Journal of Politics 80(4), 1117-1133.

Ansolabehere, Stephen and Philip Edward Jones (2010). "Constituents' Responses to Congressional Roll-Call Voting". American Journal of Political Science 54(3), 583-597.

Arnold, R. Douglas (1990). The Logic of Congressional Action. Yale University Press.

Bafumi, Joseph and Michael C. Herron (2010). "Leapfrog Representation and Extremism: A Study of American Voters and Their Members in Congress". American Political Science Review 104(3), 519-542.

Bartels, Larry M. (1996). "Uninformed Votes: Information Effects in Presidential Elections". American Journal of Political Science 37(2), 1051-1068.

Bartels, Larry M. (2008). Unequal Democracy: The Political Economy of the New Gilded Age. Princeton University Press.

Bawn, Kathleen et al. (2012). "A Theory of Political Parties: Groups, Policy Demands and Nominations in American Politics". Perspectives on Politics 10(3), 571-597.

Bonica, Adam and Gary W. Cox (2018). "Ideological Extremists in the U.S. Congress: Out of Step but Still in Office". Quarterly Journal of Political Science 13, 207-236.

Broockman, David E. (2016). "Approaches to Studying Policy Representation". Legislative Studies Quarterly 41(1), 181-215.

Broockman, David E. and Daniel M. Butler (2017). "The Causal Effects of Elite PositionTaking on Voter Attitudes: Field Experiments with Elite Communication". American Journal of Political Science 61(1), 208-221.

Bullock, John G. (2011). "Elite Influence on Public Opinion in an Informed Electorate". American Political Science Review 105(3), 496-515. 
Canes-Wrone, Brandice, David W. Brady, and John F. Cogan (2002). "Out of Step, out of Office: Electoral Accountability and House Members' Voting". American Political Science Review 96(1), 127-140.

Carson, Jamie L. et al. (2010). "The Electoral Costs of Party Loyalty in Congress". American Journal of Political Science 54(3), 598-616.

Cinelli, Carlos and Chad Hazlett (2020). "Making Sense of Sensitivity: Extending Omitted Variable Bias". Journal of the Royal Statistical Society. Series B 82(1), 39-67.

Clinton, Joshua D. (2006). "Representation in Congress: Constituents and Roll Calls in the 106th House". Journal of Politics 68(2), 397-409.

Dancey, Logan and Geoffrey Sheagley (2016). "Inferences Made Easy: Partisan Voting in Congress, Voter Awareness, and Senator Approval". American Politics Research 44(5), $844-874$.

Delli Carpini, Michael X. and Scott Keeter (1997). What Americans Know about Politics and Why it Matters. Yale University Press.

Erikson, Robert S., Michael B. Mackuen, and James A. Stimson (2002). The Macro Polity. Cambridge University Press.

Eskridge, William N. (1987). "Dynamic Statutory Interpretation". University of Pennsylvania Law Review 135, 1479-1555.

Fearon, James D. (1999). "Electoral Accountability and the Control of Politicians: Selecting Good Types versus Sanctioning Poor Performance". Democracy, Accountability, and Representation. Ed. by Przeworski, Adam, Susan Stokes, and Bernard Manin. Cambridge University Press, 55-97.

Fiorina, Morris P. (1974). Representatives, Roll calls, and Constituencies. Lexington Books. Fowler, Anthony (2020). "Partisan Intoxication or Policy Voting?" Quarterly Journal of Political Science 15, 141-179.

Fowler, Anthony and Michele Margolis (2014). "The Political Consequences of Uninformed Voters". Electoral Studies 34, 100-110. 
Gilens, Martin (2001). "Political Ignorance and Collective Policy Preferences". American Political Science Review 95(2), 379-396.

Guisinger, Alexandra (2009). "Determining Trade Policy: Do Voters Hold Politicians Accountable?" International Organization 63(3), 533-557.

Hill, Seth J. and Gregory A. Huber (2019). "On The Meaning of Survey Reports of Roll Call Votes Not Cast in a Legislature". American Journal of Political Science 63(3), 611-625.

Jessee, Stephen A. (2009). "Spatial Voting in the 2004 Presidential Election". American Political Science Review 103(1), 59-81.

Key, V. O. (1966). The Responsible Electorate: Rationality in Presidential Voting: 1936-1960. Harvard University Press.

Lax, Jeffrey R., Justin H. Phillips, and Adam Zelizer (2019). "The Party or the Purse: Unequal Representation in the US Senate". American Political Science Review 113(4), $917-940$.

Lenz, Gabriel S. (2012). Follow the Leader? How Voters Respond to Politicians' Policies and Performance. Princeton University Press.

Lupia, Arthur and Matthew D. McCubbins (1998). The Democratic Dilemma: Can Citizens Learn What They Need to Know? Cambridge University Press.

Mayhew, David (1974). The Electoral Connection. Yale University Press.

Miller, Warren E. and Donald E. Stokes (1963). "Constituency Influence in Congress". American Political Science Review 57(1), 45-56.

Nyhan, Brendan et al. (2012). "One Vote Out of Step? The Effects of Salient Roll Call Votes in the 2010 Election". American Politics Research 40(5), 844-879.

Shor, Boris and Jon C. Rogowski (2018). "Ideology and the US Congressional Vote". Political Science Research and Methods 6(2), 323-341.

Snyder, James M. and Tim Groseclose (2000). "Estimating Party Influence in Congressional Roll-call Voting." American Journal of Political Science 44(2), 193. 
Stephanopoulos, Nicholas O (2018). "Accountability Claims in Constitutional Law". Northwestern University Law Review 112(5), 989-1068.

Tausanovitch, Chris and Christopher Warshaw (2018). "Does the Spatial Proximity Between Legislators and Voters Affect Voting Decisions in U. S. House Elections?" Political Behavior 40(1), 223-245. 


\section{Online Appendix (Supporting Information)}




\section{Appendix Table of Contents}

A Data Sources and Variable Construction 1

Table A1: Data Sources . . . . . . . . . . . . . . . . . 1

Table A2: CCES Issue Questions and the Congressional Agenda . . . . . . . . 2

Table A3: Roll Call Votes and Passage Rates . . . . . . . . . . . . . . 3

B Additional Analyses 4

Table B1: Uncertainty and Correctness of Beliefs . . . . . . . . . . . . 5

Table B2: All Main Regressions with Coefficients on Control Variables . . . . 6

Table B3: Second Stage Estimates Using OLS . . . . . . . . . . . . . . . 7

Table B4: Interaction between Issues and Party Agreement . . . . . . . . . . 8

Table B5: Subgroup Analysis of 2018 Experiment . . . . . . . . . . . . 8

Figure B1: Estimates by Issue . . . . . . . . . . . . . . . . . . . 9

C Predictors of Correct Perceptions $\quad 10$

C.1 Sociodemographic Predictors . . . . . . . . . . . . . . . . . 10

Figure C1: Signal Strength and Receptivity Predict Correct Perceptions . . . 11

C.2 Time Spent on Perception Questions . . . . . . . . . . . . . . . . 11

Table C1: Descriptive Statistics of Time Spent on Answering Questions . . . 12

Table C2: Time Spent on Perception Questions and Correct Answers . . . . 13

$\begin{array}{lr}\text { D Heterogeneity Analyses } & 14\end{array}$

D.1 Heterogeneity by Political Interest . . . . . . . . . . . . . . . . 14

Table D1: Issue and Party Accountability by News Interest . . . . . . . . . . 15

D.2 Heterogeneity by Salience . . . . . . . . . . . . . . . . . 15

D.3 Heterogeneity by Close Votes, Marginal Districts . . . . . . . . . . 16

Table D2: Effects in Close Votes and Marginal Districts . . . . . . . . . . . 17

D.4 Heterogeneity by Abstentions in Roll Call Votes . . . . . . . . . . . 18

Table D3: Heterogeneity between Taken and Abstained Votes . . . . . . . . . 18

$\begin{array}{ll}\text { E Sensitivity Analysis } & 19\end{array}$

Figure E1: Sensitivity of Treatment Effects to Unobserved Confounding . . 20 


\section{A Data Sources and Variable Construction}

CCES The datasets we use for each year are listed in Table A1. Each year's CCES is composed of several team modules each with samples of 1,000 to 2,000, and share 50 or so standard questions called the Common Content.

Table A1 - Data Sources

\begin{tabular}{rrrrrr}
\hline & Year & Dataset & CDs & Observations & Questions \\
\hline 1 & 2006 & CCES 2006 Module & 291 & 1,013 & 4 \\
2 & 2007 & CCES 2007 Common Content & 437 & 10,000 & 3 \\
3 & 2008 & CCES 2008 Module & 426 & 3,000 & 4 \\
4 & 2009 & CCES 2009 Module & 437 & 6,000 & 5 \\
5 & 2010 & CCES 2010 Module & 434 & 3,000 & 5 \\
6 & 2012 & CCES 2012 Wave of 2010-2014 Panel & 436 & 19,500 & 3 \\
7 & 2013 & CCES 2013 Module & 412 & 1,500 & 2 \\
8 & 2014 & CCES 2014 Module & 412 & 1,500 & 1 \\
9 & 2015 & CCES 2015 Module & 387 & 1,000 & 1 \\
10 & 2016 & CCES 2016 Module & 436 & 3,000 & 7 \\
11 & 2017 & CCES 2017 Module & 390 & 1,000 & 4 \\
12 & 2018 & CCES 2018 Module & 433 & 2,000 & 5 \\
\hline
\end{tabular}

Note: Each year's survey sample is drawn from a part of the year's CCES. The last column indicates how many roll call perception questions were used in that module.

Key Votes The issues covered in the CCES, along with their rollcall vote outcomes, are summarized in Table A2. The votes used for agreement in this paper are bolded. Table A3 shows the result of the rollcall vote of those votes and how close each one was.

\section{Additional Details on the Operationalization of Control Variables}

Ideological Agreement Respondent's ideology is taken from their placement on a 7-point scale ranging from "Very Liberal" to "Very Conservative," standardized to range from -1 to 1. NOMINATE scores in a given Congress lie between around -1 (Democrats) and 1 (Republicans). The absolute difference between the two measures are then flipped so positive values indicate less distance, and ranges from -1 to 1 .

Ideological Distance from Challenger Distance is coded similar to agreement but on the reverse scale, so that 1 indicates the highest distance. Perception of the challenger's ideology suffers from a substantial amount of missingness in some years, because they were not uniformly asked. To preserve the sample size, we control for an indicator of missingness and impute values of mean. 
Table A2 - CCES Issue Questions and the Congressional Agenda

Note: Questions grouped by congressional session at the time of the survey. Each rows reports the question number. Questions begin with $\mathrm{CC}$ for Common Content, followed by the year, further followed by the official question number. Final passage in a chamber is indicated by "Y" (passage), "N" (vote taken but failed), and "(nv)" (chamber did not hold a floor vote). Congresses are labeled by the President, Speaker, and Senate Majority Leader at the time. Bold font indicates questions in which a perception question was asked in the module used in this paper.

\begin{tabular}{|c|c|c|c|}
\hline \multicolumn{2}{|c|}{ 109th Congress (Bush, Hastert, Frist) } & Hou. & Sen. \\
\hline CCO6_3060 & Ban Partial Birth Abortion & Y & Y \\
\hline CCO6_3063 & Fund Stem Cell 2005 & $\mathrm{Y}$ & $\mathrm{Y}$ \\
\hline cco6_3066 & Withdraw Iraq 2006 & (nv) & $\mathrm{N}$ \\
\hline CC06_3069 & Immigration Reform & (nv) & $\mathrm{N}$ \\
\hline CCO6_3072 & Raise Minimum Wage 2006 & Y & Y \\
\hline CCO6_3075 & Cut Capital Gains Tax & Y & Y \\
\hline CCO6_3078 & CAFTA & Y & Y \\
\hline
\end{tabular}

\begin{tabular}{|c|c|c|c|}
\hline \multicolumn{2}{|c|}{ 111th Congress (Obama, Pelosi, Reid) } & Hou & Sen \\
\hline CC09_59A & Ledbetter Fair Pay & $\mathrm{Y}$ & $\mathrm{Y}$ \\
\hline CCO9_59B & Hate Crime Prevention & $\mathrm{Y}$ & $\mathrm{Y}$ \\
\hline CC09_59C, CC10_332A & ARRA & $\mathrm{Y}$ & $\mathrm{Y}$ \\
\hline CC09_59D, CC10_332B & SCHIP 2009 & $\mathrm{Y}$ & $\mathrm{Y}$ \\
\hline CCO9_59E, CC10_332C & ACESA & $\mathrm{Y}$ & (nv) \\
\hline CCO9_59F, CC10_332D & PPACA & $\mathrm{Y}$ & $\mathrm{Y}$ \\
\hline CCO9_59G & Sotomayor & & $\mathrm{Y}$ \\
\hline CCO9_59H & House Bill ACA & $\mathrm{Y}$ & (nv) \\
\hline CC10_332E & Kagan & & $\mathrm{Y}$ \\
\hline CC10_332F & Dodd Frank & $\mathrm{Y}$ & $\mathrm{Y}$ \\
\hline CC10_332G & End DADT & $\mathrm{Y}$ & $\mathrm{Y}$ \\
\hline $\mathrm{CC} 10_{-} 332 \mathrm{H}$ & FISA & $\mathrm{Y}$ & $\mathrm{Y}$ \\
\hline CC10_332I & Fund Stem Cell 2007 & $\mathrm{Y}$ & $\mathrm{Y}$ \\
\hline CC10_332J & TARP & $\mathrm{Y}$ & Y \\
\hline
\end{tabular}

\begin{tabular}{|c|c|c|c|}
\hline \multicolumn{2}{|c|}{ 113th Congress (Obama, Boenner, Reid) } & Hou. & Sen. \\
\hline CC13_320A, CC14_320A & Gun Background Check & (nv) & $\mathrm{N}$ \\
\hline CC13_320B, CC14_320B & Gun No Disclosure & (nv) & $\mathrm{Y}$ \\
\hline CC13_320C, CC14_320C & Ban Hi Capacity Gun & (nv) & $\mathrm{N}$ \\
\hline CC13_320D, CC14_320D & Ban Assault Rifle & (nv) & $\mathrm{N}$ \\
\hline CC13_320E, CC14_320E & Concealed Gun Permit & (nv) & $\mathrm{N}$ \\
\hline CC13_332A, CC14_323_3 & Ban 20 week Abortion & $\mathrm{Y}$ & (nv) \\
\hline CC13_332B, CC14_325_2 & Simpson Bowles & $\mathrm{N}$ & (nv) \\
\hline CC13_332C & Repeal ACA 2013 & $\mathrm{Y}$ & (nv) \\
\hline CC13_332D & Keystone 2012 & (nv) & $\mathrm{N}$ \\
\hline CC13_332E & Sales Tax Online & (nv) & Y \\
\hline CC13_332F & Violence against Women & $\mathrm{Y}$ & $\mathrm{Y}$ \\
\hline CC13_332G, CC14_331_2 & Freedom Act 2013 & (nv) & (nv) \\
\hline CC13_332H & Student Success & $\mathrm{Y}$ & (nv) \\
\hline CC14_325_1 & Ryan Budget & $\mathrm{Y}$ & $\mathrm{N}$ \\
\hline CC14_325_3 & Extend Tax Cut & (nv) & $\mathrm{Y}$ \\
\hline CC14_325_4 & Tax Relief 2014 & Y & $\mathrm{Y}$ \\
\hline CC14_325_5 & Raise Debt Ceiling 2014 & $\mathrm{Y}$ & $\mathrm{Y}$ \\
\hline CC14_331_1 & Agriculture & $\mathrm{Y}$ & $\mathrm{Y}$ \\
\hline CC14_331_3 & End Nomination Filibuster & & $\mathrm{Y}$ \\
\hline CC14_331_4 & Relig. Exempt. ACA & (nv) & $\mathrm{N}$ \\
\hline CC14_331_5 & South Korea FTA & $\mathrm{Y}$ & $\mathrm{Y}$ \\
\hline
\end{tabular}

\begin{tabular}{ll}
\hline \multicolumn{2}{c}{ 110th Congress (Bush, Pelosi, Reid) } \\
CC07_34, cC08_316E & SCHIP \\
cC07_38, cC08_316D & FISA \\
cC06_V2072, CC08_316B & Raise Minimum Wage 2007 \\
cC07_46, cC08_316A & Withdraw Iraq 2007 \\
cC08_316C & Fund Stem Cell 2007 \\
cC08_316F & Ban Gay Marriage \\
CC08_316G & Foreclosure Assistance \\
CC08_316H & NAFTA \\
CC08_316I & TARP \\
\hline
\end{tabular}

\begin{tabular}{|c|c|c|c|}
\hline \multicolumn{2}{|c|}{ 112тh Congress (Obama, Boehner, Reid) } & \multicolumn{2}{|c|}{ Hou. Sen. } \\
\hline CC11_340a & Raise Debt Ceiling & Y & Y \\
\hline CC11_341A & ARRA & Y & Y \\
\hline CC11_341B & SCHIP 2009 & Y & Y \\
\hline CC11_341C & ACESA & Y & nv) \\
\hline CC11_341D, CC12_332I & PPACA & Y & Y \\
\hline CC11_341E, CC12_332J & End DADT & Y & Y \\
\hline CC11_341F & FISA & Y & Y \\
\hline CC11_341G & Fund Stem Cell 2007 & Y & Y \\
\hline $\mathrm{CC} 11_{-} 341 \mathrm{H}$ & TARP & Y & Y \\
\hline CC12_332A & Ryan Budget & Y & N \\
\hline CC12_332B & Simpson Bowles & $\mathrm{N}$ & nv) \\
\hline CC12_332C & Middle Class Tax Cut & (nv) & Y \\
\hline CC12_332D & Tax Relief 2012 & $\mathrm{Y}$ & Y \\
\hline CC12_332E & Relig. Exempt. ACA & (nv) & Y \\
\hline CC12_332F & South Korea FTA & Y & Y \\
\hline CC12_332G & Repeal ACA 2012 & $\mathrm{Y}$ & nv) \\
\hline CC12_332H & Keystone 2012 & (nv) & $\mathrm{N}$ \\
\hline \multicolumn{2}{|c|}{ 114th Congress (Obama, Boehner / Ryan, McConnell) } & Hou. & Sen. \\
\hline CC15_327A, CC16_351I & Repeal ACA 2015 & $\mathrm{Y}$ & (nv) \\
\hline CC15_327B & Keystone 2014 & $\mathrm{Y}$ & $\mathrm{N}$ \\
\hline CC15_327C, CC16_351G & Iran Sanction & (nv) & (nv) \\
\hline CC15_327D, CC16_351B & TPA & Y & Y \\
\hline CC15_327E & Cuba Open & $\mathrm{N}$ & (nv) \\
\hline CC15_327F1 & Renew Patriot Act & (nv) & (nv) \\
\hline CC15_327F2, & Freedom Act 2015 & $\mathrm{Y}$ & Y \\
\hline \multicolumn{4}{|l|}{ CC16_351C } \\
\hline CC15_327G, CC16_351D & TAA & Y & Y \\
\hline CC15_327H & Violence against Women & Y & Y \\
\hline CC16_351A & Garland & & (nv) \\
\hline CC16_351E & Education To States & $\mathrm{Y}$ & Y \\
\hline CC16_351F & Highway Funding & $\mathrm{Y}$ & Y \\
\hline CC16_351H & Medicare Reform & $\mathrm{Y}$ & Y \\
\hline CC16_351K & Raise Minimum Wage & (nv) & (nv) \\
\hline
\end{tabular}

\begin{tabular}{|c|c|c|c|}
\hline \multicolumn{2}{|c|}{ 115th Congress (Trump, Ryan, McConnell) } & Hou. & Sen. \\
\hline CC17_340A & Repeal ACA 2017 & (nv) & $\mathrm{N}$ \\
\hline CC17_340B & Gorsuch & & $\mathrm{Y}$ \\
\hline CC17_340C & AHCA & $\mathrm{Y}$ & (nv) \\
\hline CC17_340D & CHOICE & $\mathrm{Y}$ & (nv) \\
\hline CC17_340E & Kate's Law & $\mathrm{Y}$ & (nv) \\
\hline CC17_340F & Iran N.K. Russia Sanctions & $\mathrm{Y}$ & $\mathrm{Y}$ \\
\hline CC17_340G & No Sanctuary & $\mathrm{Y}$ & (nv) \\
\hline $\mathrm{CC} 17 \_340 \mathrm{H}$ & DeVos & (nv) & $\mathrm{Y}$ \\
\hline CC17_340I & Continue Funding & $\mathrm{Y}$ & $\mathrm{Y}$ \\
\hline
\end{tabular}


Table A3 - Roll Call Votes and Passage Rates

\begin{tabular}{|c|c|c|c|c|c|c|c|}
\hline \multirow[b]{2}{*}{ Issue } & \multirow[b]{2}{*}{ Date } & \multicolumn{3}{|c|}{ Roll Call } & \multicolumn{3}{|c|}{ Closeness } \\
\hline & & Yeas & Nays & Miss & Pass By & Party & Close \\
\hline Ban Partial Birth Abortion & $2003-06-04$ & 282 & 139 & 13 & 66 & $\mathrm{R}+23$ & \\
\hline Fund Stem Cell 2005 & $2005-05-24$ & 238 & 194 & 2 & 22 & $\mathrm{R}+29$ & $\checkmark$ \\
\hline CAFTA & $2005-07-28$ & 217 & 215 & 2 & 1 & $\mathrm{R}+29$ & $\checkmark$ \\
\hline Cut Capital Gains Tax & $2006-05-10$ & 244 & 185 & 4 & 28 & $\mathrm{R}+30$ & \\
\hline Withdraw Iraq 2008 & $2007-05-10$ & 171 & 255 & 7 & -45 & $\mathrm{D}+31$ & \\
\hline Withdraw Iraq 2007 & $2007-07-12$ & 223 & 201 & 8 & 7 & $\mathrm{D}+30$ & $\checkmark$ \\
\hline Foreclosure Assistance & $2007-08-04$ & 241 & 172 & 20 & 25 & $\mathrm{D}+29$ & \\
\hline SCHIP 2007 & $2007-09-25$ & 265 & 159 & 9 & 49 & $\mathrm{D}+31$ & \\
\hline FISA & $2008-06-20$ & 293 & 129 & 13 & 77 & $\mathrm{D}+37$ & \\
\hline Ledbetter Fair Pay & $2009-01-27$ & 250 & 177 & 6 & 34 & $\mathrm{D}+77$ & \\
\hline SCHIP 2009 & $2009-02-04$ & 290 & 135 & 8 & 74 & $\mathrm{D}+77$ & \\
\hline ARRA & $2009-02-13$ & 246 & 183 & 4 & 30 & $\mathrm{D}+77$ & \\
\hline ACESA & $2009-06-26$ & 219 & 212 & 3 & 3 & $\mathrm{D}+78$ & $\checkmark$ \\
\hline PPACA & $2010-03-21$ & 219 & 212 & 0 & 3 & $\mathrm{D}+75$ & $\checkmark$ \\
\hline Dodd Frank & $2010-06-30$ & 237 & 192 & 4 & 21 & $\mathrm{D}+77$ & $\checkmark$ \\
\hline End DADT & $2010-12-15$ & 250 & 175 & 9 & 34 & $\mathrm{D}+76$ & \\
\hline Simpson Bowles & $2012-03-28$ & 38 & 382 & 11 & -178 & $\mathrm{R}+51$ & \\
\hline Ryan Budget & $2012-03-29$ & 228 & 191 & 12 & 12 & $\mathrm{R}+51$ & $\checkmark$ \\
\hline Repeal ACA 2012 & $2012-07-11$ & 244 & 185 & 2 & 28 & $\mathrm{R}+49$ & \\
\hline Violence Against Women & $2013-02-28$ & 286 & 138 & 7 & 70 & $\mathrm{R}+31$ & \\
\hline Ban 20wk Abortion & $2013-06-18$ & 229 & 196 & 9 & 13 & $\mathrm{R}+32$ & $\checkmark$ \\
\hline Cut Food Stamps & $2013-07-11$ & 216 & 208 & 11 & 0 & $\mathrm{R}+33$ & $\checkmark$ \\
\hline Repeal ACA 2015 & $2015-02-03$ & 239 & 186 & 8 & 23 & $\mathrm{R}+57$ & $\checkmark$ \\
\hline Medicare Reform & $2015-03-26$ & 392 & 37 & 4 & 176 & $\mathrm{R}+57$ & \\
\hline Freedom Act 2015 & $2015-05-13$ & 338 & 88 & 6 & 122 & $\mathrm{R}+56$ & \\
\hline TAA & $2015-06-12$ & 126 & 302 & 6 & -90 & $\mathrm{R}+58$ & \\
\hline TPA & $2015-06-18$ & 218 & 208 & 8 & 2 & $\mathrm{R}+58$ & $\checkmark$ \\
\hline Education To States & $2015-12-02$ & 359 & 64 & 10 & 143 & $\mathrm{R}+57$ & \\
\hline Highway Funding & $2015-12-03$ & 359 & 65 & 9 & 143 & $\mathrm{R}+57$ & \\
\hline $\mathrm{AHCA}$ & $2017-05-04$ & 217 & 213 & 1 & 1 & $\mathrm{R}+45$ & $\checkmark$ \\
\hline CHOICE & $2017-06-08$ & 233 & 186 & 11 & 17 & $\mathrm{R}+44$ & $\checkmark$ \\
\hline Withold Sanctuary Funding & $2017-06-29$ & 228 & 195 & 10 & 12 & $\mathrm{R}+47$ & $\checkmark$ \\
\hline Kates Law & $2017-06-29$ & 257 & 167 & 9 & 41 & $\mathrm{R}+47$ & \\
\hline Tax Cut Jobs Act & $2017-12-20$ & 224 & 201 & 7 & 8 & $\mathrm{R}+46$ & $\checkmark$ \\
\hline Budget Bipartisan & $2018-02-09$ & 240 & 186 & 5 & 24 & $\mathrm{R}+45$ & \\
\hline Immigration Ryan & $2018-06-27$ & 121 & 301 & 6 & -95 & $\mathrm{R}+42$ & \\
\hline
\end{tabular}

Note: The "Pass By" column presents the number of Yea votes over the majority threshold. Negative values indicates the bill failed. The party column shows the majority party advantage by seats. Close votes are those between 45 to 55 percent support. Snyder and Groseclose (2000) define a "very close vote" as a vote in a 40 to 60 percent. 


\section{B Additional Analyses}

First Stage Table B1 lists out the proportion of correct responses for each issue asked. Figure B1 panel (a) shows the first stage coefficients separated out by issue.

Second Stage Table B2 shows key coefficient estimates without hiding the estimates for control variables. Table B3 displays OLS estimates for the second stage, overall and by Congress. Figure B1 panel (b) shows the OLS and IV estimates separately by issue. Table B4 models an interaction term as a third endogenous variable to the model. The substantive finding is the same: the new interaction term is negative, but is an order of magnitude smaller than the main effect.

Experiment Table B5 displays regression analysis in the $n=144$ respondents in the 2018 experiment of Table 5 who had correct priors. We ask if whether the issue treatment being correct or incorrect had differential effects on approval by including interactions with the treatment and the proportion of correct (or incorrect) information. This is a small subgroup, of course, so we are cautious in drawing strong conclusions from this finding. 
Table B1 - Uncertainty and Correctness of Beliefs

\begin{tabular}{|c|c|c|c|c|c|c|c|}
\hline \multirow[b]{2}{*}{ Issue } & \multirow[b]{2}{*}{ Congress } & \multirow[b]{2}{*}{ CCES } & \multicolumn{4}{|c|}{ Perceived Vote (proportion) } & \multirow[b]{2}{*}{$\mathrm{n}$} \\
\hline & & & Correct & $\begin{array}{l}\text { Not } \\
\text { Sure }\end{array}$ & Incorrect & $\begin{array}{c}\text { Correct } \\
\text { (two- } \\
\text { way) }\end{array}$ & \\
\hline Ban Partial Birth Abortion & 108 & 2006 & 0.40 & 0.46 & 0.13 & 0.75 & 507 \\
\hline CAFTA & 109 & 2006 & 0.33 & 0.47 & 0.20 & 0.63 & 503 \\
\hline Cut Capital Gains Tax & 109 & 2006 & 0.51 & 0.37 & 0.12 & 0.81 & 504 \\
\hline Fund Stem Cell 2005 & 109 & 2006 & 0.48 & 0.33 & 0.19 & 0.72 & 506 \\
\hline Withdraw Iraq 2007 & 110 & 2007 & 0.34 & 0.61 & 0.05 & 0.86 & 9,890 \\
\hline FISA & 110 & 2007,2008 & 0.26 & 0.66 & 0.09 & 0.75 & 11,895 \\
\hline SCHIP 2007 & 110 & 2007,2008 & 0.33 & 0.61 & 0.06 & 0.85 & 11,903 \\
\hline Foreclosure Assistance & 110 & 2008 & 0.26 & 0.57 & 0.17 & 0.60 & 2,040 \\
\hline Withdraw Iraq 2008 & 110 & 2008 & 0.32 & 0.56 & 0.12 & 0.73 & 2,035 \\
\hline Ledbetter Fair Pay & 111 & 2009 & 0.35 & 0.58 & 0.07 & 0.82 & 5,124 \\
\hline SCHIP 2009 & 111 & 2009 & 0.39 & 0.51 & 0.10 & 0.80 & 5,120 \\
\hline ACESA & 111 & 2009,2010 & 0.39 & 0.50 & 0.11 & 0.79 & 8,015 \\
\hline ARRA & 111 & 2009,2010 & 0.46 & 0.46 & 0.08 & 0.85 & 8,038 \\
\hline PPACA & 111 & 2009,2010 & 0.51 & 0.42 & 0.07 & 0.87 & 8,021 \\
\hline Dodd Frank & 111 & 2010 & 0.37 & 0.57 & 0.06 & 0.85 & 2,863 \\
\hline End DADT & 111 & 2010 & 0.25 & 0.66 & 0.08 & 0.76 & 2,860 \\
\hline Repeal ACA 2012 & 112 & 2012 & 0.69 & & 0.30 & 0.70 & 18,816 \\
\hline Ryan Budget & 112 & 2012 & 0.58 & & 0.38 & 0.61 & 18,816 \\
\hline Simpson Bowles & 112 & 2012 & 0.70 & & 0.27 & 0.72 & 18,816 \\
\hline Ban 20 week Abortion & 113 & 2013 & 0.52 & 0.25 & 0.23 & 0.69 & 1,497 \\
\hline Violence Against Women & 113 & 2013 & 0.55 & 0.20 & 0.24 & 0.69 & 1,493 \\
\hline Cut Food Stamps & 113 & 2014 & 0.38 & 0.32 & 0.30 & 0.56 & 1,488 \\
\hline TPA & 114 & 2015,2016 & 0.29 & 0.40 & 0.31 & 0.48 & 2,468 \\
\hline Education To States & 114 & 2016 & 0.41 & 0.30 & 0.29 & 0.58 & 1,445 \\
\hline Freedom Act 2015 & 114 & 2016 & 0.45 & 0.22 & 0.33 & 0.58 & 1,466 \\
\hline Highway Funding & 114 & 2016 & 0.47 & 0.31 & 0.22 & 0.68 & 2,941 \\
\hline Medicare Reform & 114 & 2016 & 0.41 & 0.25 & 0.34 & 0.55 & 1,472 \\
\hline Repeal ACA 2015 & 114 & 2016 & 0.57 & 0.20 & 0.24 & 0.71 & 2,960 \\
\hline TAA & 114 & 2016 & 0.34 & 0.20 & 0.46 & 0.42 & 1,464 \\
\hline CHOICE & 115 & 2017 & 0.40 & 0.49 & 0.11 & 0.79 & 984 \\
\hline Kate's Law & 115 & 2017 & 0.42 & 0.41 & 0.16 & 0.72 & 988 \\
\hline $\mathrm{AHCA}$ & 115 & 2017,2018 & 0.51 & 0.34 & 0.14 & 0.78 & 2,951 \\
\hline Withold Sanctuary Funding & 115 & 2017,2018 & 0.54 & 0.33 & 0.13 & 0.81 & 2,950 \\
\hline Budget Bipartisan & 115 & 2018 & 0.31 & 0.42 & 0.27 & 0.54 & 1,960 \\
\hline Immigration Ryan & 115 & 2018 & 0.38 & 0.41 & 0.21 & 0.64 & 1,949 \\
\hline Tax Cut Jobs Act & 115 & 2018 & 0.52 & 0.33 & 0.14 & 0.79 & 1,955 \\
\hline Average of Questions & & & 0.43 & 0.42 & 0.19 & 0.71 & \\
\hline Average of Observations & & all years & 0.46 & 0.42 & 0.13 & 0.75 & 168,703 \\
\hline Party Affiliation & & all years & 0.73 & 0.21 & 0.06 & 0.92 & 163,666 \\
\hline
\end{tabular}

Note: Three columns show weighted proportion of a respondent's correct answers, don't knows, and wrong answers. "two-way" correct is the proportion of correct perceptions among correct and incorrect responses. Issues are sorted by year. 
Table B2 - All Main Regressions with Coefficients on Control Variables

\begin{tabular}{|c|c|c|c|c|c|c|}
\hline & \multicolumn{3}{|c|}{ Outcome: Approval } & \multicolumn{3}{|c|}{ Outcome: Vote Choice } \\
\hline & $\begin{array}{l}(1) \\
\text { OLS }\end{array}$ & $\begin{array}{l}(2) \\
\text { IV }\end{array}$ & $\begin{array}{l}(3) \\
\mathrm{RF}\end{array}$ & $\begin{array}{c}(4) \\
\text { OLS }\end{array}$ & $\begin{array}{l}\text { (5) } \\
\text { IV }\end{array}$ & $\begin{array}{l}(6) \\
R F\end{array}$ \\
\hline Perceived Issue Agreement & $\begin{array}{c}0.39 \\
(0.006)\end{array}$ & $\begin{array}{c}0.66 \\
(0.02)\end{array}$ & & $\begin{array}{c}0.22 \\
(0.01)\end{array}$ & $\begin{array}{c}0.59 \\
(0.03)\end{array}$ & \\
\hline Perceived Party Agreement & $\begin{array}{c}0.26 \\
(0.006)\end{array}$ & $\begin{array}{c}0.22 \\
(0.009)\end{array}$ & & $\begin{array}{c}0.29 \\
(0.01)\end{array}$ & $\begin{array}{c}0.44 \\
(0.02)\end{array}$ & \\
\hline Actual Issue Agreement & & & $\begin{array}{c}0.23 \\
(0.006)\end{array}$ & & & $\begin{array}{c}0.20 \\
(0.010)\end{array}$ \\
\hline Actual Party Agreement & & & $\begin{array}{c}0.21 \\
(0.006)\end{array}$ & & & $\begin{array}{c}0.35 \\
(0.01)\end{array}$ \\
\hline Actual Ideological Agreement & $\begin{array}{c}0.39 \\
(0.010)\end{array}$ & $\begin{array}{c}0.24 \\
(0.01)\end{array}$ & $\begin{array}{c}0.48 \\
(0.01)\end{array}$ & $\begin{array}{c}0.64 \\
(0.02)\end{array}$ & $\begin{array}{c}0.27 \\
(0.02)\end{array}$ & $\begin{array}{c}0.54 \\
(0.02)\end{array}$ \\
\hline Perceived ideological distance from challenger & $\begin{array}{c}0.15 \\
(0.009)\end{array}$ & $\begin{array}{c}0.10 \\
(0.009)\end{array}$ & $\begin{array}{c}0.20 \\
(0.010)\end{array}$ & $\begin{array}{c}0.41 \\
(0.02)\end{array}$ & $\begin{array}{c}0.27 \\
(0.02)\end{array}$ & $\begin{array}{c}0.39 \\
(0.02)\end{array}$ \\
\hline Ideology $(-1$ to 1$)$ & $\begin{array}{c}0.03 \\
(0.007)\end{array}$ & $\begin{array}{c}0.04 \\
(0.006)\end{array}$ & $\begin{array}{c}0.02 \\
(0.009)\end{array}$ & $\begin{array}{c}0.06 \\
(0.02)\end{array}$ & $\begin{array}{c}0.06 \\
(0.01)\end{array}$ & $\begin{array}{c}0.04 \\
(0.01)\end{array}$ \\
\hline Ideological Moderate & $\begin{array}{c}-0.04 \\
(0.007)\end{array}$ & $\begin{array}{c}-0.02 \\
(0.007)\end{array}$ & $\begin{array}{c}-0.04 \\
(0.007)\end{array}$ & $\begin{array}{c}-0.01 \\
(0.01)\end{array}$ & $\begin{array}{c}0.03 \\
(0.01)\end{array}$ & $\begin{array}{c}0.02 \\
(0.01)\end{array}$ \\
\hline Respondent identifies as Independent & $\begin{array}{c}-0.05 \\
(0.006)\end{array}$ & $\begin{array}{c}-0.04 \\
(0.006)\end{array}$ & $\begin{array}{c}-0.07 \\
(0.007)\end{array}$ & $\begin{array}{c}0.02 \\
(0.01)\end{array}$ & $\begin{array}{c}0.06 \\
(0.01)\end{array}$ & $\begin{array}{c}0.03 \\
(0.010)\end{array}$ \\
\hline Perceived party of Rep is correct & $\begin{array}{c}0.00 \\
(0.006)\end{array}$ & $\begin{array}{c}0.00 \\
(0.006)\end{array}$ & $\begin{array}{c}-0.01 \\
(0.006)\end{array}$ & $\begin{array}{c}0.02 \\
(0.01)\end{array}$ & $\begin{array}{c}0.01 \\
(0.01)\end{array}$ & $\begin{array}{c}0.03 \\
(0.009)\end{array}$ \\
\hline Average of Outcome & 0.07 & 0.07 & 0.07 & 0.23 & 0.23 & 0.23 \\
\hline Std. Dev. of Outcome & 0.71 & 0.71 & 0.71 & 0.84 & 0.85 & 0.84 \\
\hline R-squared & 0.47 & 0.41 & 0.39 & 0.46 & 0.36 & 0.48 \\
\hline Clusters & 849 & 847 & 847 & 787 & 786 & 786 \\
\hline Observations & 42,516 & 42,417 & 42,559 & 24,032 & 23,949 & 24,051 \\
\hline
\end{tabular}

Clustered Standard Errors by Representative.

Note: Reproduces key regression tables but displays estimates for control variables. All models include fixed effects for representative (not shown) and indicators for the missingness of ideological distance, which is itself set to 0 if missing. OLS: Ordinary Least Squares, IV: Instrumental Variables, RF: Reduced form models. 
Table B3 - Second Stage Estimates Using OLS

\begin{tabular}{|c|c|c|c|c|c|c|c|c|}
\hline & \multicolumn{8}{|c|}{ Outcome: Approval } \\
\hline & All Years & $\begin{array}{c}\text { 109th } \\
(2006)\end{array}$ & $\begin{array}{c}\text { 110th } \\
(2007-08)\end{array}$ & $\begin{array}{c}\text { 111th } \\
(2009-10)\end{array}$ & $\begin{array}{c}\text { 112th } \\
(2011-12)\end{array}$ & $\begin{array}{c}\text { 113th } \\
(2013-14)\end{array}$ & $\begin{array}{c}\text { 114th } \\
(2015-16)\end{array}$ & $\begin{array}{c}\text { 115th } \\
(2017-18\end{array}$ \\
\hline Perceived Issue Agreement & $\begin{array}{c}0.38 \\
(0.006)\end{array}$ & $\begin{array}{l}0.23 \\
(0.1)\end{array}$ & $\begin{array}{c}0.51 \\
(0.01)\end{array}$ & $\begin{array}{c}0.63 \\
(0.01)\end{array}$ & $\begin{array}{c}0.36 \\
(0.009)\end{array}$ & $\begin{array}{c}0.12 \\
(0.02)\end{array}$ & $\begin{array}{c}0.21 \\
(0.02)\end{array}$ & $\begin{array}{c}0.46 \\
(0.03)\end{array}$ \\
\hline Perceived Party Agreement & $\begin{array}{c}0.26 \\
(0.006)\end{array}$ & $\begin{array}{c}0.34 \\
(0.1)\end{array}$ & $\begin{array}{c}0.18 \\
(0.01)\end{array}$ & $\begin{array}{c}0.14 \\
(0.01)\end{array}$ & $\begin{array}{c}0.29 \\
(0.008)\end{array}$ & $\begin{array}{c}0.31 \\
(0.02)\end{array}$ & $\begin{array}{c}0.32 \\
(0.02)\end{array}$ & $\begin{array}{c}0.31 \\
(0.02)\end{array}$ \\
\hline Average of Outcome & 0.07 & 0.11 & 0.04 & 0.05 & 0.10 & 0.05 & 0.05 & 0.06 \\
\hline Std. Dev. of Outcome & 0.71 & 0.70 & 0.73 & 0.68 & 0.74 & 0.70 & 0.61 & 0.69 \\
\hline R-squared & 0.47 & 0.81 & 0.45 & 0.52 & 0.55 & 0.47 & 0.39 & 0.56 \\
\hline Clusters & 849 & 271 & 441 & 438 & 398 & 430 & 434 & 435 \\
\hline \multirow[t]{3}{*}{ Observations } & 42,516 & 448 & 9,555 & 7,211 & 16,477 & 2,327 & 3,908 & 2,590 \\
\hline & \multicolumn{8}{|c|}{ Outcome: Vote Choice } \\
\hline & $\begin{array}{l}\text { All Even } \\
\text { Years }\end{array}$ & $\begin{array}{l}\text { 109th } \\
(2006)\end{array}$ & $\begin{array}{l}\text { 110th } \\
(2008)\end{array}$ & $\begin{array}{l}\text { 111th } \\
(2010)\end{array}$ & $\begin{array}{l}\text { 112th } \\
(2012)\end{array}$ & $\begin{array}{l}\text { 113th } \\
(2014)\end{array}$ & $\begin{array}{l}\text { 114th } \\
(2016)\end{array}$ & $\begin{array}{l}\text { 115th } \\
(2018)\end{array}$ \\
\hline Perceived Issue Agreement & $\begin{array}{c}0.22 \\
(0.01)\end{array}$ & $\begin{array}{l}0.16 \\
(0.2)\end{array}$ & $\begin{array}{c}0.57 \\
(0.05)\end{array}$ & $\begin{array}{c}0.52 \\
(0.04)\end{array}$ & $\begin{array}{c}0.20 \\
(0.01)\end{array}$ & $\begin{array}{c}-0.00 \\
(0.03)\end{array}$ & $\begin{array}{c}0.30 \\
(0.03)\end{array}$ & $\begin{array}{c}0.38 \\
(0.05)\end{array}$ \\
\hline Perceived Party Agreement & $\begin{array}{c}0.29 \\
(0.01) \\
\end{array}$ & $\begin{array}{l}0.44 \\
(0.2) \\
\end{array}$ & $\begin{array}{c}0.27 \\
(0.04) \\
\end{array}$ & $\begin{array}{c}0.26 \\
(0.03) \\
\end{array}$ & $\begin{array}{c}0.26 \\
(0.01) \\
\end{array}$ & $\begin{array}{c}0.47 \\
(0.04) \\
\end{array}$ & $\begin{array}{c}0.35 \\
(0.03) \\
\end{array}$ & $\begin{array}{c}0.34 \\
(0.04) \\
\end{array}$ \\
\hline Average of Outcome & 0.23 & 0.22 & 0.24 & 0.19 & 0.25 & 0.23 & 0.21 & 0.19 \\
\hline Std. Dev. of Outcome & 0.84 & 0.81 & 0.83 & 0.85 & 0.86 & 0.78 & 0.80 & 0.85 \\
\hline R-squared & 0.46 & 0.84 & 0.64 & 0.70 & 0.44 & 0.63 & 0.50 & 0.63 \\
\hline Clusters & 787 & 246 & 332 & 389 & 391 & 360 & 394 & 368 \\
\hline Observations & 24,032 & 397 & 1,405 & 2,163 & 14,806 & 1,168 & 2,538 & 1,555 \\
\hline
\end{tabular}

Note: Each column is an OLS (instead of IV) regression, with control variables not shown. Clustered standard errors by Representative in parentheses. 
Table B4 - Interaction between Issues and Party Agreement

\begin{tabular}{lccccc}
\hline & \multicolumn{2}{l}{ Outcome: } & Approval & & \multicolumn{2}{l}{ Outcome: } & Vote Choice \\
\cline { 2 - 3 } & $(1)$ & $(2)$ & & $(3)$ & $(4)$ \\
& OLS & IV & & OLS & IV \\
\hline Perceived Issue Agreement $(0-1)$ & 0.43 & 0.73 & & 0.29 & 0.57 \\
& $(0.01)$ & $(0.03)$ & & $(0.02)$ & $(0.07)$ \\
Perceived Party Agreement $(0-1)$ & 0.30 & 0.31 & & 0.36 & 0.42 \\
& $(0.01)$ & $(0.03)$ & & $(0.02)$ & $(0.06)$ \\
Interaction & -0.07 & -0.17 & & -0.12 & 0.03 \\
& $(0.02)$ & $(0.06)$ & & $(0.03)$ & $(0.11)$ \\
\hline Average of Outcome & 0.53 & 0.53 & & 0.62 & 0.62 \\
Clusters & 839 & 837 & & 778 & 777 \\
Observations & 42,254 & 42,156 & 23,817 & 23,735 \\
\hline
\end{tabular}

Note: Here both predictors and outcome variables are re-scaled to range from 0 to 1 , so that the interaction of two disagreements do not get a positive number.

Table B5 - Subgroup Analysis of 2018 Experiment

\begin{tabular}{lc}
\hline & Approval (-1 to 1) \\
\hline Correct vote info treatment (in agreement) & -0.18 \\
& $(0.12)$ \\
Incorrect vote info treatment (in agreement) & 0.35 \\
& $(0.13)$ \\
\hline Average Outcome in Control & -0.16 \\
R-squared & 0.76 \\
Observations & 143 \\
\hline
\end{tabular}

Note: See Table 5 for description on layout and the control variables not shown. 
Figure B1 - Estimates by Issue

(a) First Stage Estimates

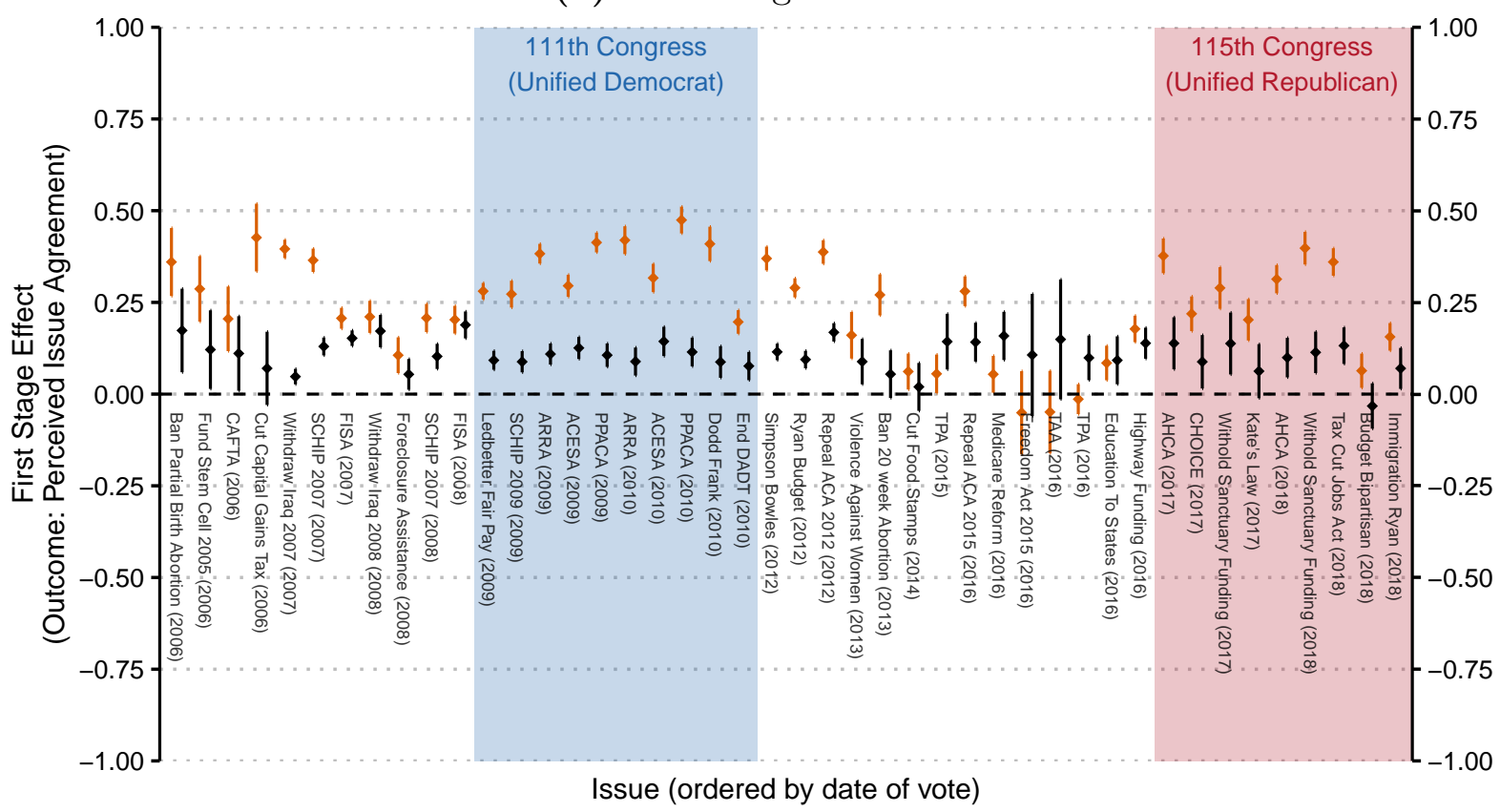

Model $\rightarrow$ First Stage of Issues Agreement $\rightarrow$ First Stage of Party Agreement

(b) Second Stage Estimates

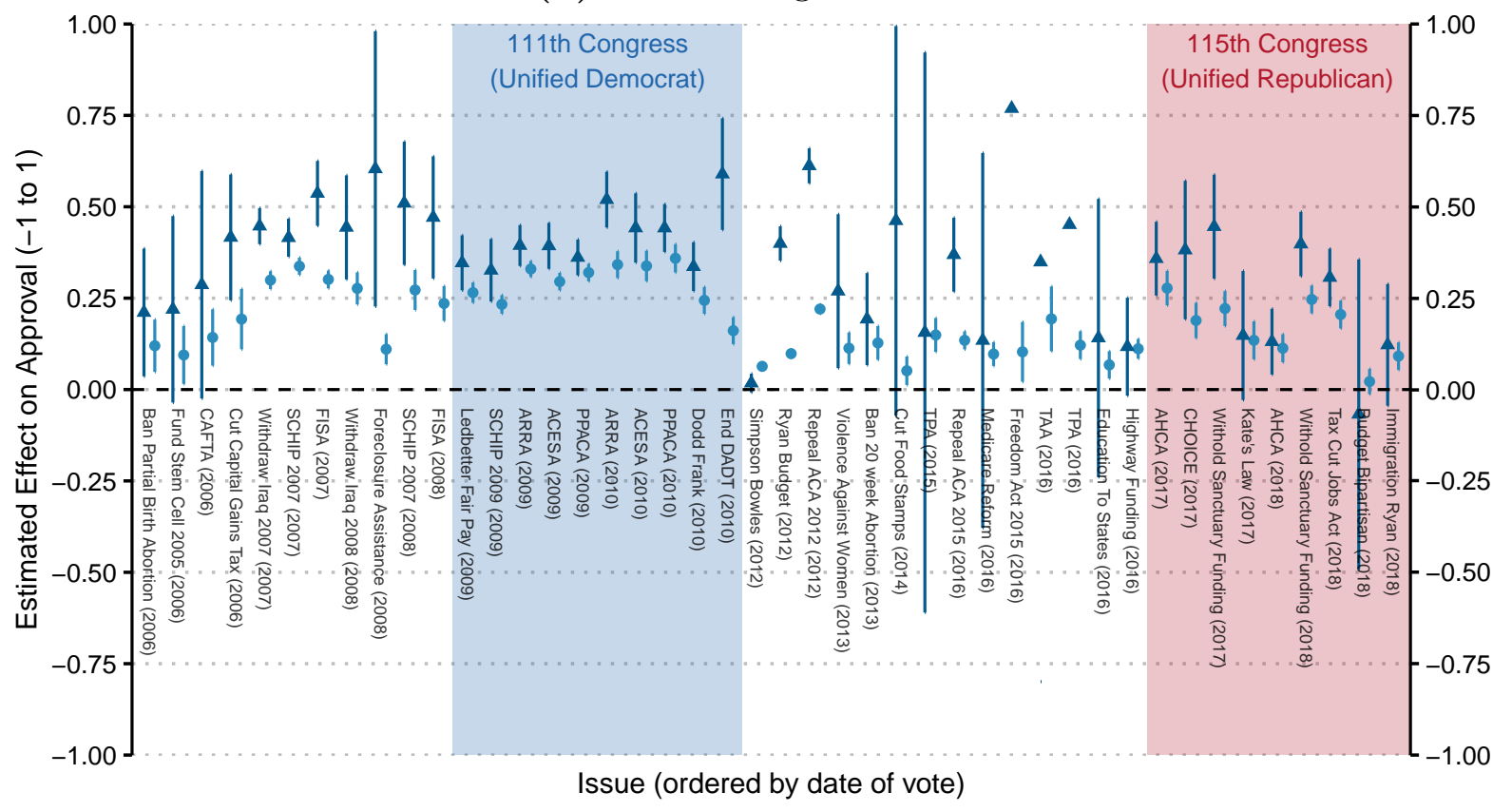

Model $\_$Instrumental Variables $\rightarrow$ OLS

Note: Model follows equations 2 and 3 in the main text but with modeling each issue separately. Intervals are 95 percent confidence intervals. 


\section{Predictors of Correct Perceptions}

This section further examines the first stage estimates. We first describe the predictors of correct predictions. Separately, we examine data on timings to ask if respondents are looking up the answers to perception questions.

\section{C.1 Sociodemographic Predictors}

We model perception formation using a two-step Heckman selection model, which corrects for potential censoring biases due to respondents who do not hazard a guess. Formally, let $D_{i}$ be an indicator for respondent $i$ providing a yes or no response to the perceived rollcall question, and let $C_{i}$ be a continuous variable that indicates the degree of correct perceptions the respondent has. $C_{i}$ can only be observed for those with $D_{i}=1$. If we let $C_{i}^{*}$ be the potentially unobserved value for all respondents, then the Heckman correction will estimate the population relationship $\mathbf{E}\left(C_{i}^{*} \mid X\right)=X \beta+\epsilon$ from the observed data and a selection

model predicting $D_{i}=1$. In our setup, the first step differentiates between people who express some belief on some roll call vote and people who said "Don't Know" on every roll call vote. The second step is whether people who express a belief hold correct ones.

Communication theory suggests three sets of predictor variables: signals, receptivity, and filters. First, the nature of the signaler likely matters. Extremism sends clearer signals than does moderation. We include the absolute value of the representatives' NOMINATE score within party to measure extremity versus moderation. We also include their years serving in Congress, because legislators might garner more understanding through their tenure. Second, receptivity to information should lead to both having a perception and reaching a correct one. We proxy this by demographic measures ranging from education to news interest. Finally, partisan and ideological information biases might filter perceptions. We include indicators of party identification, left-right ideological orientation, self-identified Independents, self-identified moderates, and actual party agreement.

Figure $\mathrm{C} 1$ plots estimated marginal effects from each stage of the Heckman model. The first panel shows the average marginal effects from a logit model predicting $D_{i}$. The second panel displays the effect of the same independent variables in explaining $C_{i}$, conditional on making some guess. Standard errors are clustered at the representative level.

By far the most important factors explaining perception formation are the ideological orientation of the representative (the nature of the signaler) and the individual's attentiveness and resources (receptivity to information), such as news interest and income. The relative contribution of these factors are similar between the first and second stage. 
Figure C1 - Signal Strength and Receptivity Predict Correct Perceptions

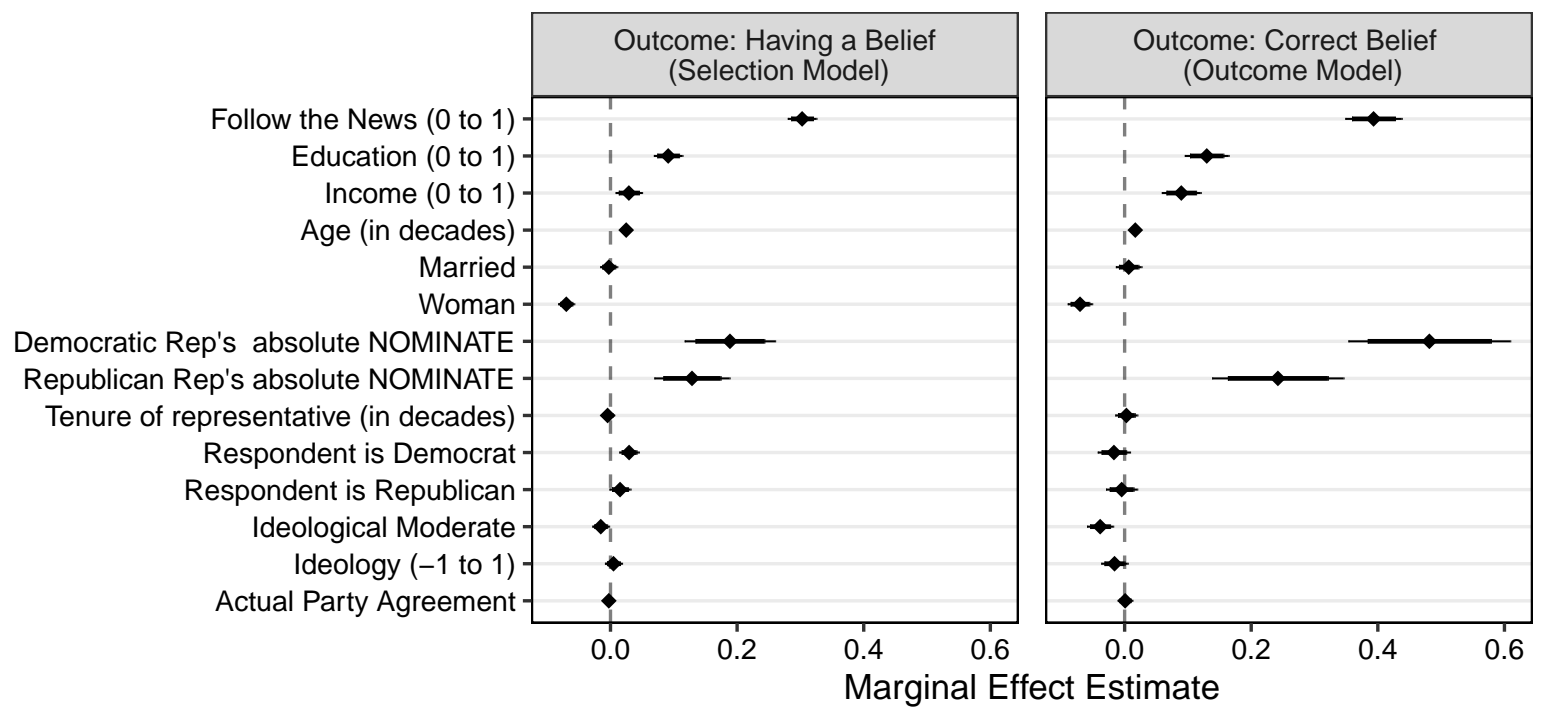

Note: Bars show 95 and 99 percent confidence intervals. NOMINATE scores are flipped so positive values of the predictor indicate more extreme voting patterns (within party).

\section{C.2 Time Spent on Perception Questions}

As an indirect test of whether respondents are looking up the correct answers to questions about their representative's roll call votes, we investigate the time a respondent takes to answer a perception question. YouGov, which runs the CCES, collects information on how many seconds a respondent took at the page-level.

One page of a perception question typically contains a one-sentence description of the bill, and three questions for each respondent's House Representative and two Senators, with a follow-up for people who responded "Not Sure." We designed the module anticipating that reading the question and the bill description will take 10-15 seconds, and answering the questions will take 5 seconds each.

Table C1 provides summary statistics of the range of seconds respondents took to answer the perception questions. We take the 2016 CCES module where seven issue perception questions were asked in succession. Each row of the table in panel (a) shows these issues in the order they appeared. We see that the median respondent takes 10-25 seconds to complete a page. As the 90th percentile shows, only 10 percent of respondents take around 50 seconds to complete a issue question. We compare this with timings of non-political questions in the same module, shown in panel (b). These questions asked about respondent's preferences on food and diet, and are a useful comparison because there would be no incentive to look up the "correct" answer for such non-political questions. We see that the range of timings are 
roughly similar, suggesting little cheating in the perception questions.

Table C1 - Descriptive Statistics of Time Spent on Answering Questions

(a) Percentiles of Seconds Spent on Issue Perception Questions

\begin{tabular}{lccccc}
\hline & $\begin{array}{c}10 \text { th } \\
(\text { secs.) }\end{array}$ & $\begin{array}{c}25 \text { th } \\
(\text { secs.) }\end{array}$ & $\begin{array}{c}50 \text { th } \\
(\text { secs.) }\end{array}$ & $\begin{array}{c}75 \text { th } \\
(\text { secs.) }\end{array}$ & $\begin{array}{c}90 \text { th } \\
(\text { secs.) }\end{array}$ \\
\hline TPP Trade Deal (82 words) & 13 & 17 & 25 & 37 & 56 \\
Education Reform (68 words) & 10 & 15 & 21 & 32 & 52 \\
Highway Funding (58 words) & 6 & 9 & 12 & 19 & 28 \\
Medicare Reform (66 words) & 6 & 9 & 14 & 22 & 37 \\
Freedom Act (64 words) & 7 & 10 & 17 & 29 & 46 \\
TAA Assistance (63 words) & 6 & 9 & 13 & 20 & 31 \\
Repeal Obamacare (50 words) & 5 & 8 & 11 & 16 & 23 \\
\hline
\end{tabular}

(b) Percentiles of Seconds Spent on Non-Political Questions

\begin{tabular}{lccccc}
\hline & $\begin{array}{c}\text { 10th } \\
\text { (secs.) }\end{array}$ & $\begin{array}{c}25 \text { th } \\
\text { (secs.) }\end{array}$ & $\begin{array}{c}50 \text { th } \\
\text { (secs.) }\end{array}$ & $\begin{array}{c}75 \text { th } \\
\text { (secs.) }\end{array}$ & $\begin{array}{c}90 t h \\
\text { (secs.) }\end{array}$ \\
\hline Magazine Readership (18 words) & 6 & 8 & 11 & 16 & 22 \\
Canned Tomatoes (63 words) & 9 & 15 & 21 & 29 & 40 \\
Salad Dressing (60 words) & 7 & 11 & 16 & 23 & 32 \\
\hline
\end{tabular}

Note: Sample taken from one of the CCES modules in 2016, $n=1,500$. Perceived vote questions ask the perceptions for three offices, while we use only the responses for the US House.

But the distribution of time spent cannot ascertain whether people who take more time than others are looking up the answers online, genuinely debating the answer, or are simply distracted by their daily lives. If they are indeed taking time to look up the answers, longer times should correlate with more correct answers. We test this possibility by estimating the linear probability model of the form:

$$
C_{i j}=\gamma_{0}+\gamma_{1} s_{i j}+\text { Issue } \mathrm{FE}_{j}+\text { Respondent } \mathrm{FE}_{i}+\varepsilon_{i j}
$$

where $C_{i j}$, following the previous section, is 1 if respondent $i$ answers correctly for issue question $j$, and 0 otherwise. Our coefficient of interest is $\gamma_{1}$ on the variable $s_{i j}$, or the seconds it took respondent $i$ to answer question $j$. We can also include issue fixed effects (FE) to account for the variation in length and difficulty of each of the seven questions, as well as respondent fixed effects to account for the within-respondent tendency to take time.

Estimates suggest that to the extent that respondents take more time to answer a question, they are less certain and less correct in their answers - the opposite of what we would expect if they had been using that extra time to look up the correct answers. Table C2 columns (1) - (3) shows the estimates of $\gamma_{1}$ across specifications. The coefficients are substantially small and, if anything, negative. One extra second spent on answering a question 
is associated with a $0.2-0.3$ percentage points decrease in the probability of getting that answer correct. In columns (4) - (6), we replace the outcome with an indicator for being Not Sure on the same question. An extra second spent on a question is associated with a $0.3-0.4$ percentage point increase in being unsure. We do not necessarily interpret these coefficients causally: a more plausible interpretation is that the types of questions that take any given respondent more time are genuinely those where the respondent is not sure, does not look up the answers, and therefore less likely to be correct.

Table C2 - Time Spent on Perception Questions and Correct Answers

\begin{tabular}{lcccccccc}
\hline & \multicolumn{2}{c}{ Outcome: Correct Perception } & & \multicolumn{3}{c}{ Outcome: Not Sure } \\
\cline { 2 - 3 } & $(1)$ & $(2)$ & $(3)$ & & $(4)$ & $(5)$ & $(6)$ \\
\hline Seconds Spent on Page & -0.0030 & -0.0020 & -0.0024 & & 0.0039 & 0.0033 & 0.0037 \\
& $(0.0003)$ & $(0.0003)$ & $(0.0004)$ & & $(0.0004)$ & $(0.0004)$ & $(0.0004)$ \\
\hline Respondent-Issue Pairs & 9,996 & 9,996 & 9,996 & & 9,996 & 9,996 & 9,996 \\
Issue Fixed Effects & & $\checkmark$ & $\checkmark$ & & & $\checkmark$ & $\checkmark$ \\
Respondent Fixed Effects & & & $\checkmark$ & & & $\checkmark$ \\
\hline
\end{tabular}

Note: Each column is a regression, with clustered standard errors by respondent in parentheses. Sample taken from one of the CCES modules in 2016, $n=1,500$, where each respondent answered perception questions on seven bills. Observations of less than 2 seconds or more than 200 seconds are excluded as outliers. 


\section{Heterogeneity AnAlyses}

Here we examine if our key IV estimates change systematically by four types of important covariates: voter's political interest (Section D.1), issue salience (Section D.2), pivotality of the representative's vote (Section D.3), and member's abstention (Section D.4).

\section{D.1 Heterogeneity by Political Interest}

Our findings may not be generalizable to the public if the CCES sample is disproportionately knowledgeable about politics. In this appendix section, we find that it is unlikely that the choice of our survey sample overestimates the size of accountability we report.

Online surveys like the CCES tends to be attract more political knowledgeable respondents compared to other modes, but not by much. First, while becoming a panelist is opt-in, answering the CCES is not, because the survey firm uses a matched sampling frame and draws panelists to form a representative sample in terms of demographics and political interest. A 2014 study $^{2}$ addressed this question by comparing surveys of the same questions on three different modes: mail, phone, and a CCES module. The online sample was about 10 percentage points more likely to correctly know the unemployment rate, and party control of the House. Among internet users, the difference in these political knowledge questions was about 5 percentage points but difficult to distinguish from zero.

The question of generalizability hinges not only on whether the CCES sample is more knowledgeable than the general population, but also to the extent to which political knowledge affects our outcome of interest. Published analysis of other outcome variables of the CCES do not indicate that differences in the demographic composition is consequential. ${ }^{3}$ We approximate tests like this with the outcome in our main findings below.

Table D1 shows our key coefficients estimated by instrumental variables, but running a separate regression for each group of news interest: we classify "Not Sure", "From Time to Time", and "Hardly at all" as Low interest, "Some of the Time" as Some, and "Most of the Time" as High. ${ }^{4}$ If our findings were driven by high-interest constituents, we would only find effects among the last group.

We find that although the effects of accountability are sometimes higher among high

2 Ansolabehere, Stephen, and Brian F. Schaffner (2014). "Does Survey Mode Still Matter? Findings from a 2010 Multi-mode Comparison." Political Analysis, 22(3), 285-303.

3 Ansolabehere and Schaffner (2014) cited above demonstrates this. For an example using vote outcomes, see Ansolabehere, Stephen, and Douglas Rivers (2013). "Cooperative Survey Research." Annual Review of Political Science, 16(1), 307-329.

4 The prompt was "Some people seem to follow what's going on in government and public affairs most of the time, whether there's an election going on or not. Others aren't that interested. Would you say you follow what's going on in government and public affairs ..." 
interest constituents, the pattern is not consistent and constituents with low news interest still exhibit sizable effect sizes. The estimated effect of (instrumented) perceived issue agreement on vote is nearly 0.60 among high interest voters and 0.40 among low interest voters. Yet constituents with some news interest have the largest coefficient. When the outcome is approval, the pattern is if anything reversed, where low interest voters exhibit higher effects. Perceived party agreement (instrumented) exerts the largest effect among low interest constituents, and the effect sizes decreases by news interest. In contrast, actual ideological agreement has the largest effect among high interest constituents.

Table D1 - Issue and Party Accountability by News Interest

\begin{tabular}{lcccccccc}
\hline & \multicolumn{3}{c}{ Outcome: Approval } & & \multicolumn{2}{c}{ Outcome: Vote Choice } \\
\cline { 2 - 3 } & $(1)$ & $(2)$ & $(3)$ & & $(4)$ & $(5)$ & $(6)$ \\
& Low & Some & High & & Low & Some & High \\
\hline Perceived Issue Agreement & 0.72 & 0.59 & 0.64 & & 0.50 & 0.78 & 0.58 \\
& $(0.19)$ & $(0.06)$ & $(0.02)$ & & $(0.29)$ & $(0.14)$ & $(0.03)$ \\
Perceived Party Agreement & 0.30 & 0.27 & 0.19 & & 0.96 & 0.61 & 0.29 \\
& $(0.05)$ & $(0.02)$ & $(0.01)$ & & $(0.09)$ & $(0.05)$ & $(0.02)$ \\
Actual Ideological Agreement & 0.03 & 0.15 & 0.32 & & 0.08 & 0.16 & 0.39 \\
& $(0.04)$ & $(0.03)$ & $(0.01)$ & & $(0.06)$ & $(0.05)$ & $(0.03)$ \\
\hline Average of Outcome & 0.06 & 0.09 & 0.06 & & 0.16 & 0.23 & 0.25 \\
Clusters & 750 & 804 & 821 & & 633 & 689 & 750 \\
Observations & 4,885 & 9,136 & 28,135 & & 3,305 & 5,071 & 15,359 \\
\hline
\end{tabular}

Note: Each column is a regression and standard errors clustered by representative are in parentheses. News interest is a 5-point ordinal question asked 2007 onwards. Estimates are IV regressions detailed in equation 3 where perceived issue and party agreement instrumented by actual issue and party agreement.

\section{D.2 Heterogeneity by Salience}

Another source of obvious heterogeneity suggested by the literature is issue salience. Salience can mean at least four different things. We consider each in turn, though we leave more detailed analysis for future work.

One definition of salience is informational (or cognitive, as opposed to value-based) and internal to the public (as opposed to defined by the media or politicians). This internal information salience is measured by our first stage estimates in Figure B1 panel (a). We see that in President Obama's second term, roll call votes have small or even negligible first stages, and there are not many roll call votes that made it to a floor vote to begin with. A weak first stage therefore has a substantive interpretation. It means that the degree to which the issue and polices are understood by the voter is low. 
A weak first stage statistically leads to a noisy and unreliable instrumental variables estimate, as confirmed in the outsized confidence intervals of Figure B1 panel (b). This estimate on Perceived Issue Agreement in equation (3) can be interpreted as a measure of internal value salience. If voters cared a lot about the issue, they would be more likely to change their approval of their legislator because of it. Figure B1 suggests that issues with low internal value salience were concentrated in President Obama's second term.

We can also measure salience externally, defined as the degree to which the media or politicians talk about the issue. We examined Pew's measure of what the public perceived as the "Most Important Priority" (MIP) in each year. We take the top 5 issues in each year and code our roll call vote "salient" (as an external matter) if it squarely falls into that category. ${ }^{5}$

This distinction, which we can call salience measured by external information salience, turns out not to matter on average. The $t$-test between the issue-specific IV coefficients for year-specific MIP issues gives a difference of $t=1.32(p=0.20)$. We also consider health care bills, as health care is arguably the defining issue of the decade - an issue where parties took highly contrasting positions, affected everyone, and was the focus of many Congresses. However, the $t$-test of coefficients with healthcare vs. non-healthcare issues is also not significant, $t=0.39(p=0.70)$.

Yet another definition of salience is whatever the Congress and party leaders find important enough to put on the agenda. By this definition, all our issues are salient because they were chosen from a list of key votes in each year. This is a measure of external value salience.

\section{D.3 Heterogeneity by Close Votes, Marginal Districts}

Constituents may hold individual legislators accountable only when their rollcall vote was pivotal, although in the main text we assume otherwise for simplicity. Here we examine whether results by the closeness of the vote and the marginality of the member. We define a marginal member as a member within \pm 20 members from the median all in terms of NOMINATE at the time of each vote, i.e. the 45-55 percentile. And we call a vote as close if its final voteshare is also 45-55 percent. In other words, we use the ex ante marginality of the member and the ex post closeness of the final rollcall vote. This operationalization can be scrutinized further - in some sense, no single member is pivotal in a rollcall that is

\footnotetext{
5 One problem with this classification is that Pew or Gallup's categories are likely too broad to capture salience of the types of particular issues we measure. For example, the bill on withholding funding to sanctuary cities (2018) has one of the highest first stage effects in our data as well as a high IV estimate, but most news organizations did not ask about this in their MIP measure. Dodd-Frank (2010) is another that does not easily fall into one of the provided categories.
} 
Table D2 - Effects in Close Votes and Marginal Districts

\begin{tabular}{|c|c|c|c|c|c|}
\hline & \multicolumn{5}{|c|}{ Outcome: Approval } \\
\hline & $\begin{array}{l}\text { (1) } \\
\text { All }\end{array}$ & $\begin{array}{c}(2) \\
\text { Lopsided Vote } \\
\text { Safe MC }\end{array}$ & $\begin{array}{c}(3) \\
\text { Lopsided Vote } \\
\text { Marginal MC }\end{array}$ & $\begin{array}{c}(4) \\
\text { Close Vote } \\
\text { Safe MC }\end{array}$ & $\begin{array}{c}(5) \\
\text { Close Vote } \\
\text { Marginal MC }\end{array}$ \\
\hline Perceived Issue Agreement & $\begin{array}{c}0.35 \\
(0.008)\end{array}$ & $\begin{array}{c}0.33 \\
(0.009)\end{array}$ & $\begin{array}{c}0.31 \\
(0.03)\end{array}$ & $\begin{array}{c}0.40 \\
(0.01)\end{array}$ & $\begin{array}{c}0.38 \\
(0.03)\end{array}$ \\
\hline Perceived Party Agreement & $\begin{array}{c}0.46 \\
(0.008)\end{array}$ & $\begin{array}{c}0.47 \\
(0.008)\end{array}$ & $\begin{array}{c}0.48 \\
(0.03)\end{array}$ & $\begin{array}{c}0.44 \\
(0.009)\end{array}$ & $\begin{array}{c}0.42 \\
(0.03)\end{array}$ \\
\hline Average of Outcome & 0.07 & 0.07 & 0.07 & 0.06 & 0.06 \\
\hline Clusters & 847 & 835 & 387 & 831 & 354 \\
\hline \multirow[t]{3}{*}{ Observations } & 143,391 & 77,416 & 8,453 & 50,636 & 5,592 \\
\hline & \multicolumn{5}{|c|}{ Outcome: Approval } \\
\hline & $\begin{array}{l}\text { (1) } \\
\text { All }\end{array}$ & $\begin{array}{c}(2) \\
\text { Lopsided Vote } \\
\text { Safe MC }\end{array}$ & $\begin{array}{l}\text { (3) } \\
\text { Lopsided Vote } \\
\text { Marginal MC }\end{array}$ & $\begin{array}{c}(4) \\
\text { Close Vote } \\
\text { Safe MC }\end{array}$ & $\begin{array}{c}(5) \\
\text { Close Vote } \\
\text { Marginal MC }\end{array}$ \\
\hline Perceived Issue Agreement & $\begin{array}{c}0.30 \\
(0.01)\end{array}$ & $\begin{array}{c}0.26 \\
(0.02)\end{array}$ & $\begin{array}{c}0.23 \\
(0.05)\end{array}$ & $\begin{array}{c}0.38 \\
(0.02)\end{array}$ & $\begin{array}{c}0.38 \\
(0.07)\end{array}$ \\
\hline Perceived Party Agreement & $\begin{array}{c}0.71 \\
(0.01)\end{array}$ & $\begin{array}{c}0.71 \\
(0.02)\end{array}$ & $\begin{array}{c}0.74 \\
(0.05)\end{array}$ & $\begin{array}{c}0.70 \\
(0.02)\end{array}$ & $\begin{array}{c}0.72 \\
(0.06)\end{array}$ \\
\hline Average of Outcome & 0.23 & 0.24 & 0.23 & 0.22 & 0.24 \\
\hline Clusters & 788 & 770 & 324 & 752 & 300 \\
\hline Observations & 79,377 & 43,087 & 4,545 & 27,969 & 3,105 \\
\hline
\end{tabular}

Note: Clustered standard errors by representative. Columns (2) - (5) are subsets of the overall group shown in column (1).

decided by more than one vote - but this follows conventions in past empirical literature.

To allow the results to change by issue, we take a different form of the data where each observation is a person-issue combination. We then run the IV regression for each of the 2 by 2 combination. Table D2 shows the results. Coefficients do not appear to change by the marginality of the member, but they are perhaps somewhat larger in close votes than in lopsided vote. The first result is somewhat difficult to interpret. We may be finding no difference either because the constituent does not know or care about the MC's pivotality in the vote, or it may be that the member in the median 10 percent of the NOMINATE distribution may actually not have been pivotal in some votes. The second comparison suggests that constituents perhaps exert more control in close votes. However, it may be that close votes are inherently controversial and lopsided ones are, naturally, consensual for the constituents. 


\section{D.4 Heterogeneity by Abstentions in Roll Call Votes}

Given our results, one might suspect that members have an incentive to obscure their position when they want to vote on clearly unpopular issues. The final heterogeneity analysis we conduct is whether missed or abstained votes lead to different constituent reactions. Here we again use person-issue level data to account for the fact that the representative will take different actions on different votes in the same year. Then we estimate separate regressions for abstained and taken votes. The overall rate of abstention can be seen in Table A3.

In our IV regressions, we use the actual votes as an instrument. But for abstained votes, the actual issue agreement is 0 , so there is no variation in that instrument to use for estimating a coefficient. Therefore, we can only use the OLS here. The coefficient estimates may be biased but can be compared with the full regressions in Table B3.

Table D3 shows the results for Approval and OLS. The coefficients on issues are similar and so there are no noticeable differences. We again add the caveat that these are only OLS estimates.

Table D3 - Heterogeneity between Taken and Abstained Votes

\begin{tabular}{lcccccc}
\hline & \multicolumn{2}{c}{ Outcome: Approval } & & \multicolumn{2}{c}{ Outcome: Vote Choice } \\
\cline { 2 - 3 } \cline { 6 - 6 } & $\begin{array}{c}(1) \\
\text { Taken Votes }\end{array}$ & $\begin{array}{c}(2) \\
\text { Abstention }\end{array}$ & & $\begin{array}{c}(3) \\
\text { Taken Votes }\end{array}$ & $\begin{array}{c}(4) \\
\text { Abstention }\end{array}$ \\
\hline Perceived Issue Agreement & 0.21 & 0.20 & & 0.14 & 0.10 \\
& $(0.003)$ & $(0.022)$ & & $(0.005)$ & $(0.039)$ \\
Perceived Party Agreement & 0.43 & 0.43 & & 0.56 & 0.47 \\
& $(0.006)$ & $(0.031)$ & & $(0.010)$ & $(0.094)$ \\
\hline Average of Outcome & 0.07 & 0.03 & & 0.23 & 0.29 \\
Clusters & 847 & 154 & & 789 & 105 \\
Observations & 141,082 & 2,309 & & 79,897 & 1,094 \\
\hline
\end{tabular}

Note: OLS estimates similar to Table B3 but with subgroups. Clustered standard errors in parentheses. 


\section{E Sensitivity Analysis}

Most of our observational analyses rest on selection-on-observable assumptions for coefficient estimates to be unbiased. Therefore we perform a series of sensitivity analyses that ask whether our results are sensitive to unobserved and unmeasured confounders and the omitted variable bias they induce. It is well-known that variables that are both correlated with the outcome and correlated with the treatment variable can induce omitted variable bias. Cinelli and Hazlett (2020) outline a method that parameterizes the magnitude of the bias by the partial $R^{2}$ of the two relationships and generates benchmarks of the size of the bias. Their method extends classic sensitivity analyses but in a more readily interpretable way, because the partial $R^{2}$ is invariant to the unit of measurement and more easily interpretable.

Figure E1 shows the result of their method for different regressions. All regressions used the variable for Actual Issue Agreement as the main treatment variable of interest. Contour lines show the value of the coefficient on that variable in different settings for various degrees of confounding of an unobserved Actual Issue Agreement (the horizontal axis) or the regression outcome (the vertical axis). The top two graphs show the reduced form regression on the outcome (equation 1), using approval (left) and vote choice (right). The bottom graph show the first stage regression on issues (equation 2), where the outcome is Perceived Issue Agreement. We benchmark the possible level of unobserved confounding by an observed variable we know to be strongly of the outcome - Actual Party Agreement (denoted "Copartisan" in the graphs). Each red point shows the estimated effect of Actual Issue Agreement on the outcome if the unobserved confounder was as strong $(1 \times)$ or twice as $(2 \times)$ strong than Actual Party Agreement, or co-partisanship. The triangles show the reported value from the regular regressions where there are implicitly assumed to be no unobserved confounders.

We see in the Figure that the positive contribution of issue agreement is largely robust to our main outcome variables. The fact that each " $1 \times$ Copartisan" point lies on a contour line that is positive indicates that even if the true relationship between actual issue agreement were confounded by an unobserved that is as strong as the contribution of co-partisanship, the coefficient would still be positive. The points " $2 \times$ Copartisan" shows the same pattern, with the reduced form on vote choice being an exception. However, it is difficult to think of any confounder not already in the regression that is twice as strong copartisanship in shaping a respondent's voting behavior in the U.S. House.

Appendix Page 19 
Figure E1 - Sensitivity of Treatment Effects to Unobserved Confounding
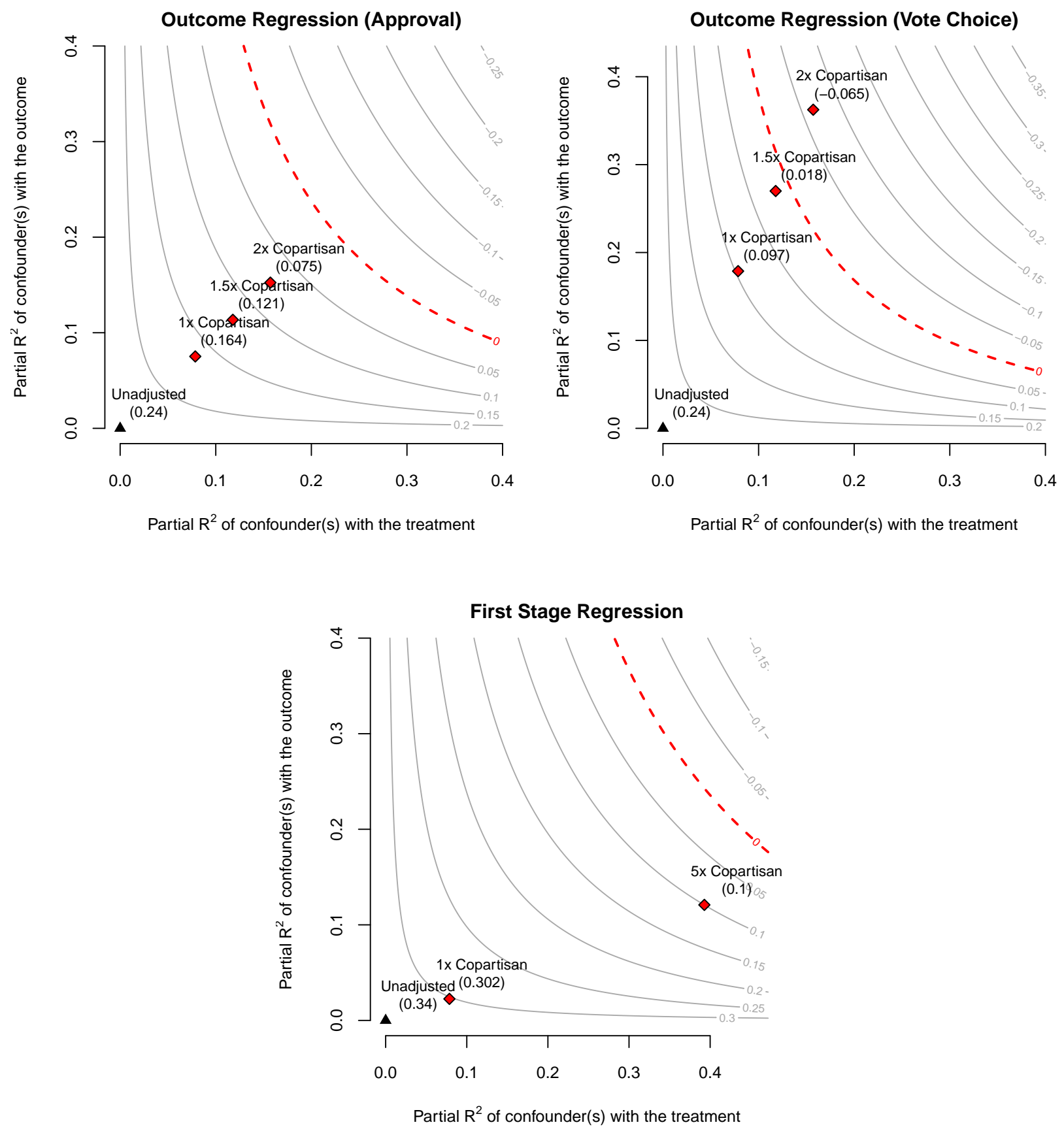

Note: Each plot shows the sensitivity of our main treatment variable - issue agreement for some of the main regressions in this paper. Each plot shows the degree of confounding between the unobserved confounder(s) and our treatment variable in the $\mathrm{x}$-axis and the degree of confounding between the unobserved confounder(s) and our outcome variable in the y-axis; the values of the contour indicate the coefficient on our treatment variable in given the degree of confounding. See text for details. 